IZA DP No. 9506

On the Impact of Quotas and Decision Rules in Ultimatum Collective Bargaining

Robert Feicht

Veronika Grimm

Holger A. Rau

Gesine Stephan

November 2015 


\title{
On the Impact of Quotas and Decision Rules in Ultimatum Collective Bargaining
}

\author{
Robert Feicht \\ Public Administration of Bavaria \\ Veronika Grimm \\ Friedrich-Alexander-University Erlangen-Nuremberg \\ Holger A. Rau \\ University of Göttingen \\ Gesine Stephan \\ $I A B$, Friedrich-Alexander-University Erlangen-Nuremberg \\ and IZA
}

\section{Discussion Paper No. 9506 \\ November 2015}

\author{
IZA \\ P.O. Box 7240 \\ 53072 Bonn \\ Germany \\ Phone: +49-228-3894-0 \\ Fax: +49-228-3894-180 \\ E-mail: iza@iza.org
}

\begin{abstract}
Any opinions expressed here are those of the author(s) and not those of IZA. Research published in this series may include views on policy, but the institute itself takes no institutional policy positions. The IZA research network is committed to the IZA Guiding Principles of Research Integrity.

The Institute for the Study of Labor (IZA) in Bonn is a local and virtual international research center and a place of communication between science, politics and business. IZA is an independent nonprofit organization supported by Deutsche Post Foundation. The center is associated with the University of Bonn and offers a stimulating research environment through its international network, workshops and conferences, data service, project support, research visits and doctoral program. IZA engages in (i) original and internationally competitive research in all fields of labor economics, (ii) development of policy concepts, and (iii) dissemination of research results and concepts to the interested public.
\end{abstract}

IZA Discussion Papers often represent preliminary work and are circulated to encourage discussion. Citation of such a paper should account for its provisional character. A revised version may be available directly from the author. 
IZA Discussion Paper No. 9506

November 2015

\section{ABSTRACT}

\section{On the Impact of Quotas and Decision Rules in Ultimatum Collective Bargaining*}

We conduct multi-person one-shot ultimatum games that reflect important aspects of collective bargaining. In all treatments a proposer has to divide a pie among herself and two groups of three recipients each. She cannot discriminate within, but across groups. A committee with representatives from one or both groups takes acceptance decisions. In a $2 \times 2$ design we vary (i) representation in the decision committee (one vs. both groups) and (ii) the decision rule (unanimity vs. majority voting). We find that (i) representation of a group in the committee is crucial for receiving a significant share, (ii), proposals are balanced only if both groups have veto power (iii) negotiations often fail if the decision environment gives insufficient guidance on what an appropriate proposal is and (iv) non-binding communication substantially reduces rejection rates and proposer shares.

JEL Classification: $\quad$ C92, C72, C78, J31, J52

Keywords: multi person ultimatum game, dictator game, collective decisions, experiments

Corresponding author:

Veronika Grimm

Friedrich-Alexander-University Erlangen-Nuremberg

Lange Gasse 20

90403 Nuremberg

Germany

E-mail: veronika.grimm@fau.de

\footnotetext{
* We thank Carlos Alós-Ferrer and Martin Kocher for helpful discussion and seminar participants in Cologne, Berlin, Nuremberg, Regensburg, and Zurich for helpful comments. We also thank Christian Sölch for excellent research assistance. Financial support by BMFSFJ (Bundesministerium für Familie, Senioren, Frauen und Jugend) of the Federal Republic of Germany and the Emerging Field Initiative (EFI) of FAU Erlangen-Nuremberg is gratefully acknowledged.
} 
It turns out that replication of all four treatments with upfront communication among the proposer and responders in a chat significantly affects outcomes. First, and most impressively, rejection rates are zero in all treatments. Second, proposer shares are significantly and substantially lower. Third, non-representation and the lack of veto power still has a clear effect on the share of the weak group. Whereas all participants receive almost equal shares if both groups have veto power ( $16 \%$ for the proposer and $14 \%$ for all others), members of the weak group receive less otherwise. Representation in the decision committee (and therefore also in the chat) without veto power helps to increase their share. However, the group does not achieve the level of the strong groups. Non-representation in the decision committee (and therefore also absence in the chat) thus implies that members of the weak group do not benefit from upfront communication at all, whereas members of the strong group clearly do.

Our findings suggest that the particular environment of a bargaining process is of crucial importance for its outcome. Discrimination seems to be particularly easy (psychologically and institutionally) if a group has no representatives in the negotiation process. This effect is not alleviated (but probably even strengthened) by communication. Fairness concerns that come up can be washed away upfront and acceptance rates of discriminating proposals increase. Informal communication seems crucial to ensure success of negotiations if the environment gives rise to uncertainty concerning the nature of appropriate proposals. In contrast, full representation of interest groups and the requirement of unanimity sets clear standards for feasible proposals, such that communication is not even essential for acceptance. In the presence of communication we find convincing support for focal point theory (cf., Alós-Ferrer and Kuzmics, 2013, among others), since all proposers suggest the unique fair allocation. In our data analysis we also point to gender effects that we discuss in a separate section. In particular, women claim less for themselves as a proposer and are more likely to accept proposals as a responder.

The paper is organized as follows. In section 2 we review the related literature. Section 3 introduces the experimental design, followed by some theoretical considerations and hypotheses in section 4 . In section 5 we report our results. Section 6 concludes.

\section{Related Literature}

In this section we review the related literature on experimental bargaining. Our collective bargaining game combines components of the ultimatum game (Güth et al., 1982) and the dictator game (e.g., Kahneman et al., 1986; Forsythe et al., 1994). Güth et al. (1982) were the first to experimentally study bargaining among a proposer and a responder in the so called "Ultimatum Game". They show that responders frequently reject low offers and that proposers offer substantial amounts. ${ }^{4}$ The

in Antitrust Experiments (Andersson and Wengström, 2007; Cooper and Kühn, 2014; Fonseca and Normann, 2012).

${ }^{4}$ Under the assumption of selfish and rational players the second mover would accept any nonnegative amount and thus, the proposer would offer the minimum amount possible. 
results have been replicated in various studies across the world. ${ }^{5}$ As the game we analyze is a mixture of multi-player ultimatum and dictator games, we selectively review the literature on group decision making in these games.

We first discuss ultimatum games where groups of first and/or second movers decide simultaneously. ${ }^{6}$ Robert and Carnevale (1997) report that groups of two and four proposers offer significantly smaller amounts to a responder than individuals. Knez and Camerer (1995) study ultimatum games where one proposer separately bargains with two responders. In this game all players were given outside options. ${ }^{7}$ The authors report that outside options cause high rejection rates (50\%) in the ultimatum game. Riedl and Vyrastekova (2003) investigate a three-player ultimatum game where one proposer plays with two responders. The authors compare treatments with different consequences of rejections. In one treatment no one earns anything after a rejection. In another treatment only responders who reject earn zero. However, if the other responder accepts, she and the proposer receive the offered amount. In a last treatment responders even receive the amount offered to the other responder if they accept but the other rejects. The study finds heterogeneous behavior in the sense that half of the responders showed no concern for the second responder, while the other half does react. Messieck et al. (1997) study the impact of decision rules ("conjunctive rule" vs. "disjunctive rule") in ultimatum games with five responders. Under the conjunctive rule (disjunctive rule) a proposal is accepted if it was as least as high as the highest (lowest) minimum acceptable offer stated by responders. The data shows that proposals are in general slightly higher when the "conjunctive rule" is applied. Bornstein and Yaniv (1998) find in group ultimatum games that groups of three proposers offer smaller amounts than individuals. They also find that responder groups accept lower proposals than individuals which leads to a higher acceptance rate.

Dufwenberg and Muren (2006) analyze group decision making in dictator games. They find that gender composition crucially matters for groups of three dictators who decide on one recipient. The authors report that the most generous groups are those composed of two men and one woman. Cason and Mui (1997) study dictator games where dictators make decisions individually and in groups of two. The results show that group decisions were more generous as compared to individual decisions. Luhan et al. (2007) extend their setting to group decisions in teams of three dictators. In contrast to Cason and Mui (1997) they find that groups of dictators behave less altruistic as compared to individuals.

The most related strand of literature are bargaining studies with two recipients in different roles. Güth and van Damme (1998) were the first to conduct a three-person mixed ultimatum-dictator game with two recipients. In their setting, one recipient has decision power (as a responder in the

\footnotetext{
${ }^{5}$ Bearden (2001) reviews ultimatum game experiments and finds that the data is robust for many experiments and even holds for different stake sizes (Cameron, 1999).

${ }^{6}$ There is a large literature about group decision making which in general finds for strategic games that groups' decisions are more rational, i.e., they do a better job in signaling games (Cooper and Kagel, 2005) and guessing games (Kocher and Sutter, 2005).

${ }^{7}$ More precisely, the proposer plays an independent game with each of the two second movers. When a second mover rejects an offer she and the first mover receive the outside option.
} 
ultimatum game) and the other one does not (as a receiver in the dictator game). The authors report that proposers offer a very low share to receivers. Importantly, responders do not care very much for receivers. In their data they cannot attribute a single rejection to the low share sent to the receiver. Güth et al. (2007) study the aforementioned setup in a large field experiment with more than 5000 newspaper readers to compare student behavior (of lab participants) to non-student behavior. The authors find that older participants and women propose more egalitarian distributions. Kagel and Wolfe (2001) modify the three-person ultimatum game of Güth and van Damme (1998) in two dimensions: (i) the responder- and receiver-roles are randomly assigned after the proposer has made her decision; (ii) a consolation prize was introduced for the non-responder. The data shows no reduction of rejection rates in the presence of a consolation prize. ${ }^{8}$ Another three-player mixed ultimatum/dictator game was conducted by Bereby-Meyer and Niederle (2005). In the experiment proposers suggest a division of a pie among themselves, a responder and a receiver. If the responder accepts the proposal, the suggested division is implemented. Treatments differ with respect to the consequences of a rejection. In one treatment the receiver gets a rejection payoff if the responder rejects, but the responder and the proposer get nothing. In another treatment the proposer gets a rejection payoff. The authors find that responders are more willing to reject proposals when the receiver receives the rejection payoff as compared to the case where proposers would get it.

Our experiment builds on the literature discussed above to analyze the effect of the institutional environment on the outcome of a collective bargaining process. We develop a multi person mixed ultimatum/dictator game where the proposer simultaneously bargains with two groups of three members each. Members of the same group have to be treated equally. A decision committee decides on the proposal. The committee consists of three recipients who represent either one, or both groups. The decision is made by majority voting or requires unanimity, depending on the treatment. Our game thus contains elements from ultimatum and dictator games and enables us to analyze the effect of (non)representation of a group in the decision committee and veto power on the final allocation as well as on rejection rates (efficiency).

To get a better idea of how bargaining is organized in one of the settings mentioned in the introduction - collective wage agreements - , an accompanying project conducted a number of semistructured interviews with representatives of German employee associations and unions (Gärtner et al., 2015). These interviews provided several interesting insights. Wage negotiations are typically conducted by negotiation committees, which are part of larger decision committees. According to the interviewees, codes of practice and legislation often implement quotas for different groups, however, women are often under-represented in decision-making and especially in negotiating committees. An often observed feature of wage negotiations is that committee members tend to meet informally upfront for discussions. Selected aspects from these interviews are taken up in our analysis.

\footnotetext{
${ }^{8}$ The finding is surprising as rejections under consolation prize lead to strong inequity between responders and the receiver.
} 


\section{The Experimental Design}

In our experiment we study the impact of (i) the composition of the bargaining committee and (ii) the decision rule employed for collective decision making on the outcome of the bargaining process in a $2 \times 2$ design. In all treatments participants played a simple one shot bargaining game among seven players in different roles. One participant acted as a proposer. He or she had to propose a division of Euro 100 among the seven participants involved in the game. The remaining six participants (the recipients) were assigned to two groups of equal size. The proposer was restricted to divisions of the pie that allocated the same amount to all recipients belonging to the same group, but he could discriminate among groups. Three out of the six recipients in both groups were assigned the role of responders, the remaining three were receivers. Responders had decision power in the sense that they collectively decided to accept or reject the proposal (for details on the decision rule, see below). Whereas receivers had no decision power and were similar to receivers in a dictator game. Upon acceptance the proposed division was implemented; upon rejection all seven participants received zero payoffs.
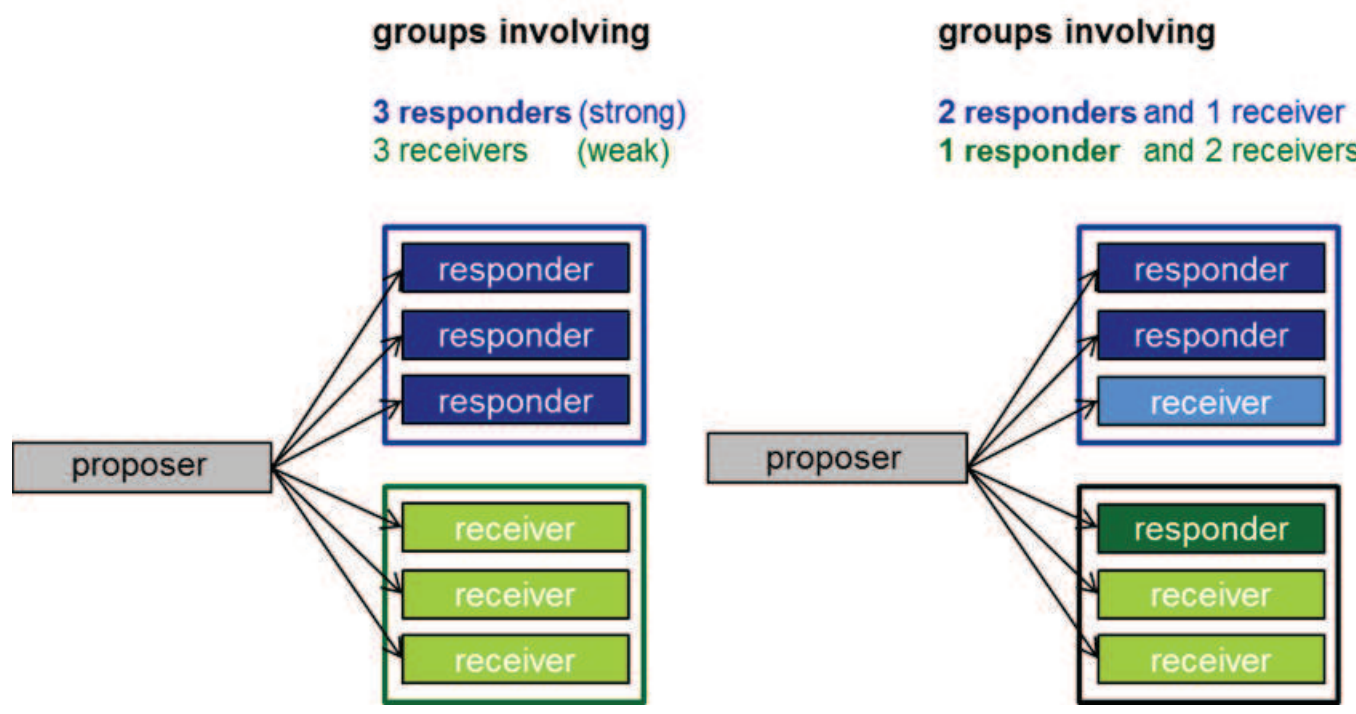

Figure 1: Possible group compositions $(3: 0 ; 2: 1)$ in the bargaining game.

In our first set of experiments we varied the following two dimensions in a $2 \times 2$ factorial design: the composition of the decision committee and the decision rule employed for the collective decision to accept or reject the offer. The decision committee was either composed of three individuals of only one group (blue or green) [treatments 30], or it contained two individuals from one group and one from the other [treatments 21]. Thus, representation of the two groups in the decision committee was always asymmetric, where the extent of asymmetry varied. The two possible cases are illustrated in Figure 1. Second, we varied the decision that the decision committee applied to collectively make the decision to accept or reject the proposal. The unanimity rule (U) was applied in two treatments, and the majority rule (M) in two other treatments. Table 1 summarizes our four treatments. 


\begin{tabular}{lccc}
\hline \hline & & \multicolumn{2}{c}{ Decision Rule } \\
& & Unanimity (U) & Majority (M) \\
\hline \multirow{2}{*}{ Decision Committee Composition } & 30 & U30 & M30 \\
& 21 & U21 & M21 \\
\hline \hline
\end{tabular}

Table 1: Treatments

In a second set of experiments we ran the same $2 \times 2$ factorial design, adding a five minute chat among the proposer and the members of the decision committee before the multi-person ultimatum game was played.

In all treatments participants had to complete an extensive questionnaire on personal characteristics and attitudes towards the experimental setting after the experiment. For all roles (proposer, responder, receiver) we recruited $50 \%$ male and female participants respectively, which allows us to investigate gender specific behavioral patterns. All experimental sessions were computerized using z-Tree (Fischbacher, 2007) and were conducted at the Laboratory of Experimental Research Nuremberg (LERN) in February 2013. Additional sessions with upfront communication were conducted in the DICE Lab in Düsseldorf in May 2014. The instructions for the unanimity treatments (U21 and U30), translated into English, are provided in Appendix B. Recruitment took place using ORSEE (Greiner, 2004).

In total, 686 subjects participated in the experiments. We have sixteen independent observations per treatment for the setup without upfront communication and 9 (U30, U21), respectively 8 (M30, M21) independent observations for the setup with upfront communication. Sessions lasted approximately 60 minutes. Individual earnings ranged from zero to 55 Euros excluding the show up fee of 2.50 Euro. Average earnings ranged from Euro 8.93 (U30) to Euro 14.29 (U21 and all treatments with upfront communication) with an overall average of Euro 12.69.

\section{Theoretical Considerations and Hypotheses}

The multi person bargaining game we analyze experimentally has a straightforward equilibrium if all players are selfish and rational. The latter is common knowledge among the players. If some or all players have social preferences, however, the analysis of the game is more interesting. In this section we provide some theoretical results for the case that players are inequality averse, which seems a natural phenomenon in the situation at hand. In order to capture a dimension that may be a key driver of treatment differences in our experiment we analyze the game under the assumption that the proposer faces uncertainty concerning the exact specifications of the Fehr-Schmidt (1999) utility functions of the members of the decision committee.

Consider the multi person mixed Ultimatum/Dictator game among seven players, the principal (p), three members of the strong group (s), and three members of the weak group (w). ${ }^{9}$ The proposer

\footnotetext{
${ }^{9}$ We simplify notation by using the indices $s$ and $w$ for any member of the respective group and will point explicitly to it if we refer to particular members.
} 
has to divide a given pie among the seven players such that (i) all money is distributed and (ii) each member of the strong and the weak group, respectively, receives an equal amount. Denote the shares offered to the individual players by the proposer by $x_{p}, x_{s}$, and $x_{w}$, respectively. Note that the rules of the game imply in all treatments

$$
x_{p}+3 x_{s}+3 x_{w}=1 .
$$

If we make the innocuous assumption that $x_{p} \geq \max \left\{x_{s} ; x_{w}\right\}$ and denote the proposal by $x=$ $\left(x_{p}, x_{s}, x_{w}\right)$ Fehr and Schmidt (1999) utility functions are given by

$$
\begin{array}{crl}
u_{p}\left(x, \beta_{p}\right) & =x_{p} & -\frac{\beta_{p}}{6}\left[3\left(x_{p}-x_{s}\right)+3\left(x_{p}-x_{w}\right)\right], \\
u_{s}\left(x, \alpha_{s}, \beta_{s}\right) & =x_{s}-\frac{\alpha_{s}}{6}\left[x_{p}-x_{s}+3 \max \left\{x_{w}-x_{s}, 0\right\}\right] & -\frac{\beta_{s}}{6}\left[3 \max \left\{x_{s}-x_{w}, 0\right\}\right], \\
u_{w}\left(x, \alpha_{w}, \beta_{w}\right) & =x_{w}-\frac{\alpha_{w}}{6}\left[x_{p}-x_{w}+3 \max \left\{x_{s}-x_{w}, 0\right\}\right]-\frac{\beta_{w}}{6}\left[3 \max \left\{x_{w}-x_{s}, 0\right\}\right],
\end{array}
$$

The parameter $\alpha$ measures the utility loss from disadvantageous inequality, while the parameter $\beta$ measures utility loss from advantageous inequality. Various papers, among them Blanco et al. (2011) show that $\alpha$ and $\beta$ parameters vary substantially across individuals. From the proposer's point of view, in our setup this would imply that she faces uncertainty concerning these parameters. In our analysis we focus on predicted treatment differences in such a setup, i.e. differences in optimal proposals and rejection probabilities. For ease of exposition we consider a purely selfish proposer. ${ }^{10}$

To begin with, we assume that inequality averse agents, while they dislike unfavorable inequality more than favorable inequality $\left(\alpha_{i}>\beta_{i} \forall i\right)$, either feel strong (or not) about both, i.e. $\beta_{i}=s \alpha_{i}$, $s \in(0,1)$. Note that under these assumptions a proposal which is accepted by committee member $i$ is also accepted by any committee member from the same group ( $s$ or $w$ ) who is less inequality averse than $i{ }^{11}$ Furthermore, we assume that from the proposer's point of view $\alpha_{i}$ are independent random variables that are identically distributed across all recipients on $[0, \bar{\alpha}]$ with distribution $F(\alpha) .{ }^{12}$ Those assumptions enable us to make use of the concept of order statistics in order to analyze proposer decisions. In the following we denote by $\alpha_{(k: n)}$ the $k^{t h}$ order statistic of $n$ independent random draws from distribution $F(\alpha)$ on $[0, \bar{\alpha}]{ }^{13}$

Now consider the decision problem of the proposer. We assume that the proposer is risk neutral. In the outlined framework, a given proposal implies different acceptance probabilities in the different

\footnotetext{
${ }^{10}$ Note that all results are qualitatively the same as long as $\beta_{p}<\frac{6}{7}$ : With the help of (1) we can simplify (2) to $u_{p}\left(x_{p}, \beta_{p}\right)=\frac{\beta_{p}}{6}+x_{p}\left(1-\frac{7}{6} \beta_{t}\right)$. Thus, $\beta_{p}<\frac{6}{7}$ ensures that the proposers' dislike of favorable inequality is not strong enough to induce her to propose equal shares for all players, including herself.

${ }^{11}$ This is due to the fact that a lower value of $\alpha$ implies both, less aversion against unfavorable and unfavorable inequality, see also the appendix.

${ }^{12}$ Group status (strong or weak) might affect standards with respect to social preferences. Thus, an alternative assumption might be that $\alpha$ and $\beta$ parameters are independently and identically distributed within a group (strong or weak), but not necessarily across groups.

${ }^{13}$ See equation (14) to (17) for the corresponding distributions and more detailed explanations of the concept.
} 
treatments, since the decision rule and the committee composition imply different requirements for acceptance of a proposal. Consider first the situation where only the strong group is represented in the committee (U30 and M30). In U30, all members of the strong group have to accept the proposal. Thus, the "critical responder" is the most inequality averse responder among the three members of the decision committee. The proposer thus maximizes her expected utility by choosing the proposal that optimally trades off acceptance probability and proposer share, where the relevant probability distribution results from using the third order statistic, denoted $\alpha_{s(3: 3)}$. Analogously, in M30, the proposer has to satisfy the member with the second highest $\alpha$, i.e. $\alpha_{s(2: 3)}$ is relevant to determine her expected payoff. More formally, the proposal should thus maximize her expected utility,

$$
E\left[u_{p}\left(x, \beta_{p}\right)\right]=P\left(u_{s}\left(x, \alpha_{s(k: 3)}\right) \geq 0\right) u_{p}\left(x, \beta_{p}\right),
$$

where $k=3$ in $\mathrm{U} 30$ and $k=2$ in $\mathrm{M} 30$, and $P\left(u_{s}\left(x, \alpha_{s(k: 3)}\right) \geq 0\right)$ denotes the probability that $u_{s}\left(x, \alpha_{s(k: 3)}\right) \geq 0$.

Now consider the situation where both groups are represented in the decision committee (U21 and M21). In U21 the proposer would be constrained by the requirement that the proposal is acceptable for both members of the strong group in the decision committee, i.e. $\alpha_{s(2: 2)}$ determines the acceptance probability. Moreover, the committee member from the weak group has to be willing to accept, i.e. $\alpha_{w(1: 1)}$ is also relevant. In U21, the proposer's objective function is thus

$$
E\left[u_{p}\left(x, \beta_{p}\right)\right]=P\left(u_{s}\left(x, \alpha_{s(2: 2)}\right) \geq 0\right) P\left(u_{w}\left(x, \alpha_{w(1: 1)}\right) \geq 0\right) u_{p}\left(x, \beta_{p}\right)
$$

Finally, consider M21. In M21, the proposer has two possibilities to get a majority of votes from the decision committee. Either the proposal convinces both committee members from the strong group (then, $\alpha_{s(2: 2)}$ is relevant); or she convinces one committee member from the strong and the weak group's committee member (then, $\alpha_{s(1: 2)}$ and $\alpha_{w(1: 1)}$ are relevant). In M21, the objective function is thus

$E\left[u_{p}\left(x, \beta_{p}\right)\right]=\max \left\{P\left(u_{s}\left(x, \alpha_{s(2: 2)}\right) \geq 0\right) u_{p}\left(x, \beta_{p}\right), P\left(u_{s}\left(x, \alpha_{s(1: 2)}\right) \geq 0\right) P\left(u_{s}\left(x, \alpha_{w(1: 1)}\right) \geq 0\right) u_{p}\left(x, \beta_{p}\right)\right\}$

In the appendix we prove the following

Proposition 1 (i) Proposer shares satisfy $x_{p}^{U 21}<x_{p}^{U 30}<x_{p}^{M 30}$ and $x_{p}^{U 30}<x_{p}^{M 21}$ if the proposer does not award a positive share to weak group members if they have no veto power.

(ii) a) Responder shares satisfy $x_{s}^{U 21} \approx x_{w}^{U 21}$, where members of the weak group receive slightly less if shares are not exactly equal. b) In U30, M30, and M21, if the critical responder exhibits a low degree of inequality aversion $\left(\alpha \leq \frac{6}{6 s-1}\right)$, the profit maximizing proposal implies $x_{w}^{U 30}=$ $x_{w}^{M 30}=x_{w}^{M 21}=0$. Otherwise the profit maximizing proposal satisfies $x_{s}=x_{w}$, even if members of the weak group have no veto power. c) Proposals that offer equal shares to both groups are 
more likely optimal in U30 than in M30. d) In M21 proposals that offer similar, but low shares to both groups can be optimal.

(iii) Ex ante (non-binding) communication decreases rejection rates.

Proof See Appendix A.1

Proposition 1 reveals some interesting facts about optimal proposals in our four treatments. Proposers should optimally claim a lower share if more groups have veto power (in U21) and if a higher number of responders have to agree, i.e. under unanimity (see part (i) of the proposition). The shares that should optimally be awarded to the two groups also depend crucially on the treatment. In U21 both groups have veto power and therefore, theory predicts that they are offered approximately equal shares. In all other treatments, the (from the proposer's point of view) optimal distribution of shares depends on the degree of inequality aversion of the critical responder. If the critical responder is expected to show a low degree of inequality aversion, the proposer maximizes her expected payoff by not offering a positive share to members of the weak group. If, on the contrary, the critical responder is expected to be extremely inequality averse, an equal split among all recipients is optimal. Note that this observation is particularly important in treatments U30 and M30. In U30, all responders have to be convinced by the proposal, in M30 only two out of three responders. Thus, in expectation the critical responder is more inequality averse in U30, an equal split is more likely optimal and the optimal proposer share (that maximizes the proposer's expected payoff) is lower.

Hypothesis 1 (Proposals) Proposer shares are lowest in U21 and lower under unanimity than under majority voting. Members of the weak group receive weakly more if they are represented in the decision committee. They should receive almost the same offers as members of the strong group if they have veto power.

Now let us consider some conjectures concerning the rejection rates. Note that in in U30, any proposal that awards zero shares to members of the weak group incurs a certain risk of rejection, since also the most inequality averse agent might not be convinced. In M30, rejection of those proposals is less likely, since acceptance could be achieved by just a majority of the decision committee. Let us mention a further issue that we did not explicitly model but which may also drive rejection rates in our experiment. Suppose that a proposer expects responders to be extremely inequality averse, but contrary to our assumption that aversion to favorable and unfavorable inequality are perfectly correlated $\left(\beta_{i}=s \alpha_{i}\right)$, suppose that with positive probability the proposer faces also responders that do not object to favorable inequality. Then, any proposal has a significant probability of rejection: Proposals with equal shares could be unattractive for responders who object only to unfavorable inequality (those with a low $\beta$-value). Proposals with unequal shares could be unattractive for responders that object to both, favorable and unfavorable inequality. The more prominent this problem becomes, the higher should be the risk of rejection. Those considerations suggest that in U30 (where the most inequality averse agent is crucial) we should observe higher rejection rates than in the other treatments. 
Now consider the cases where the weak group is represented in the decision committee. In U21 members of the weak group have to be accounted for due to their veto power. This implies that U21 is the only treatment where there is clearly no ambiguity when it comes to the nature of the optimal proposal. Proposals observed in U21 should allocate comparable amounts to the strong and the weak group (at the cost of a lower proposer share, see above) and rejection rates are likely to be low. Finally, consider M21. Here, the proposer has the option to either achieve acceptance by convincing the two members of the strong group in the decision committee or, alternatively, achieve acceptance by one member of each group - whichever is cheaper in expectation. Proposals should be less homogenous and rejections might occur since proposals that address the member of the weak group are necessarily risky. From our considerations we state the following hypothesis:

Hypothesis 2 (REJeCtion RATEs) Rejection rates should be highest in U30, intermediate in M30 and M21, and lowest in U21.

Finally, consider ex ante communication among the proposer and the committee members. Theory suggests that this should decrease rejection rates. To see this, consider the possible causes for a rejection: First, the proposer could intentionally run the risk of rejection in order to increase her share of the pie. The incentive to do so is not removed by ex ante communication since responders have no possibility to convince the proposer that they would reject offers that involve excessive claims by the proposer. Second, rejections could stem from the fact that the proposer is uncertain with respect to the intensity of inequality aversion of the responders. Obviously, in this respect the responders have a clear incentive to reveal their true preferences and thus, ex ante non-binding communication makes it less likely that distribution among the members of the strong and the weak group proposed is not in line with the preferences of the responders. Theory would thus predict that rejection rates are lower and more similar across treatments with ex ante communication. In line with the second interpretation, several representatives of collective bargaining parties in Germany mentioned in qualitative interviews (Gärtner et al., 2015) that an important function of - often confidential or semi-confidential - ex ante communication is to reveal what results would be enforceable within the respective bargaining parties. So-called "non-talks" serve the important function to informally inform the other side about red lines that cannot be crossed in negotiations. We can conclude:

Hypothesis 3 (Ex Ante Communication) Ex ante communication reduces rejection rates in U30, M30, and M21, and leads to more similar rejection rates across treatments.

\section{Results}

This section contains all our results. We first report proposer behavior, i.e. average amounts allocated to both groups, in section 5.1. In 5.2 we analyze in detail the patterns of responder behavior. Finally, in section 5.3 we report our results on the impact of ex ante non-binding communication on the outcomes in our four treatments. Finally, we analyze the content of the chat protocols. 
For all non-parametric tests we report two-sided p-values throughout this paper.

\subsection{Proposer Behavior}

Figure 2 shows average proposals in our four treatments. In all treatments proposers claim a large part of the pie for themselves. In treatments U30, M30 and M21 they claim roughly one third of the pie. These are the treatments where only the strong group can in principle make credible claims for a positive share, since the weak group has no veto power. In U21, where the weak group has veto power, proposers still claim $27 \%$ of the pie. However, they claim significantly less than in the treatments where the weak group has no veto power (Mann-Whitney test, $\mathrm{p}$-value $=0.054$ (U21 vs. $\mathrm{U} 30) ; \mathrm{p}$-value $=0.088(\mathrm{U} 21$ vs. M30) $) \cdot{ }^{14}$

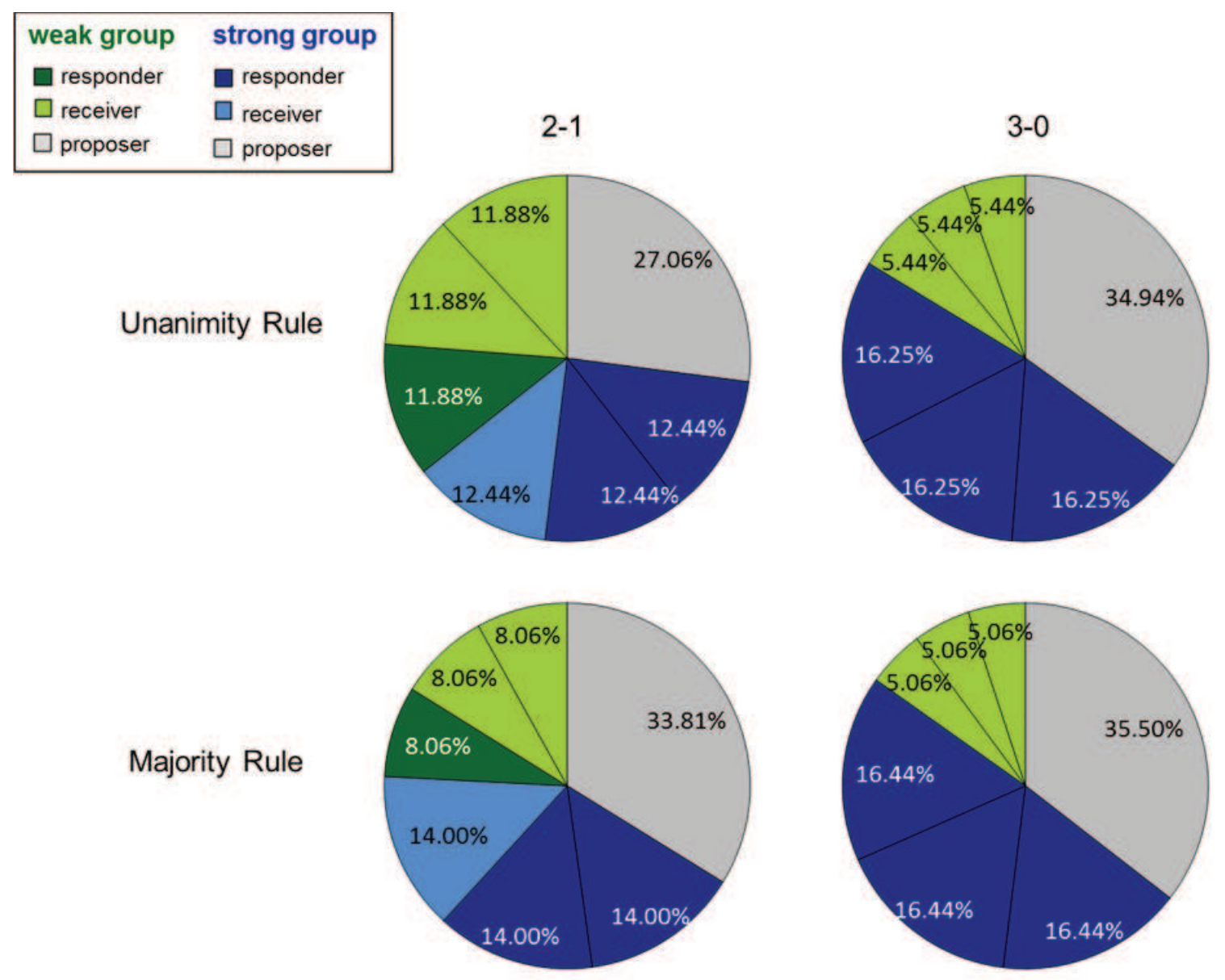

Figure 2: Average division of the pie.

The share offered to members of the weak group clearly depends on their bargaining power. If the weak group is not represented in the decision committee (see right column of Figure 2) its members receive the lowest offers of all treatments (on average 5.44\% in U30 and 5.06\% in M30).

\footnotetext{
${ }^{14}$ Mann-Whitney tests show no significant differences for all other pairwise comparisons when comparing proposers' parts in the other treatments.
} 
Under majority rule, representation in the committee weakly increases the share offered to members of the weak group. ${ }^{15}$ When deciding under unanimity rule, members of the weak group are offered the highest share if they are represented in the committee and have veto power. Then, their share $(11.88 \%)$ is significantly higher than without veto power ${ }^{16}$ and not substantially different from the share offered to members of the strong group (on average 12.44\%). ${ }^{17}$

In line with the results reported above, members of the strong group are offered a considerable share (16\% each) if the weak group is not represented in the decision committee (in M30 and U30), while they are offered less if the weak group is represented (in M21 and U21). ${ }^{18}$ Obviously, proposers account for the restrictions imposed by the environment very much in line with Hypothesis 1.

Figure 3 provides the distribution of offers to the weak and the strong group in our different treatments. In each graph the amount offered is depicted on the $\mathrm{x}$-axis (remember that only integer amounts could be offered), and the relative frequency of each offer is measured on the y-axis.
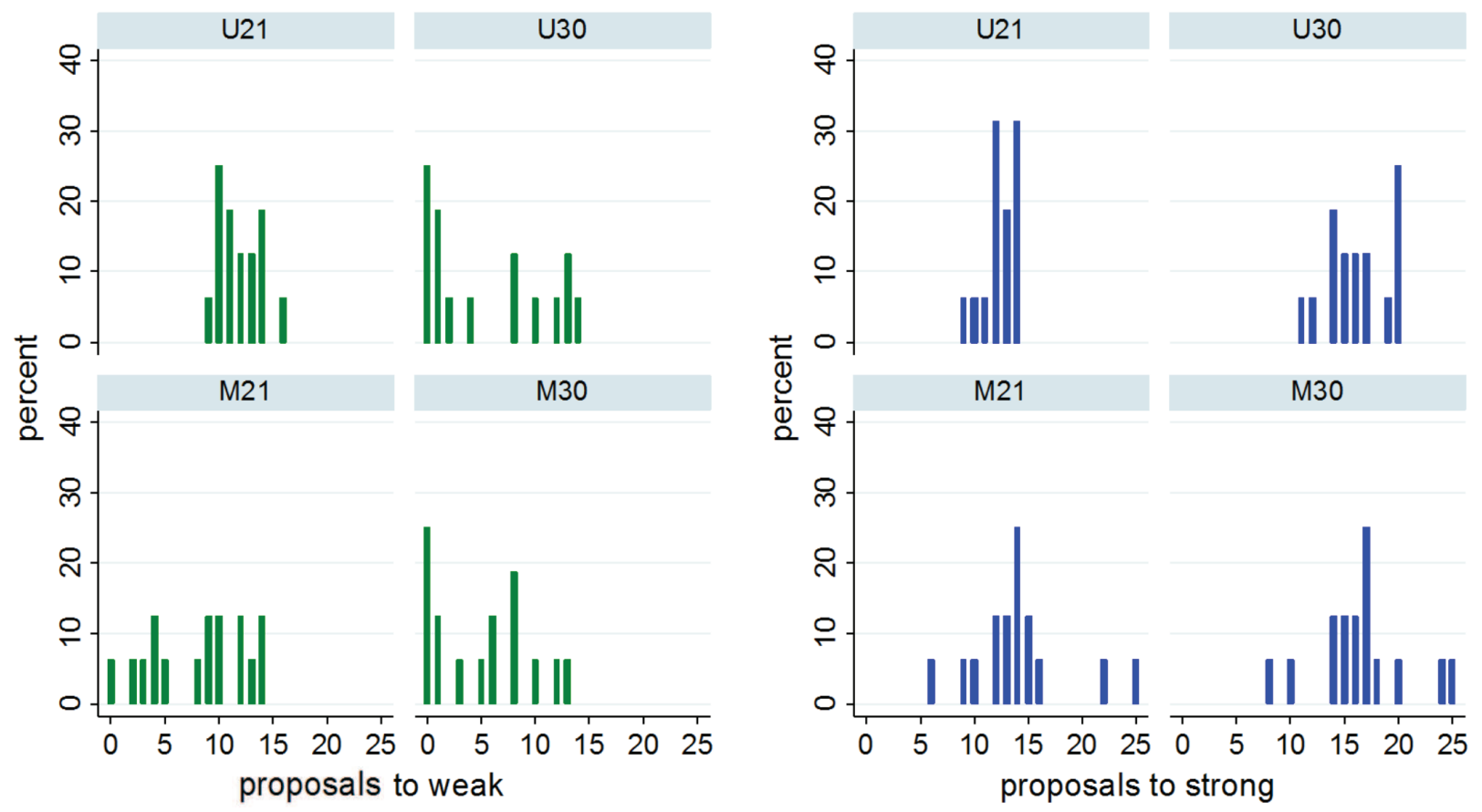

Figure 3: Distribution of the proposals to the weak and strong group.

It turns out that the distribution of proposals to the weak group (see the four graphs on the left in Figure 3) clearly differs in U21 as compared to the other treatments. In particular, proposers never

\footnotetext{
${ }^{15}$ Mann-Whitney test $\mathrm{p}$-value $\left.=0.064\right)$.

${ }^{16}$ Mann-Whitney test, $\mathrm{p}$-value $=0.002$.

${ }^{17}$ We find a weakly significant difference for a two-tailed Wilcoxon matched pairs test (p-value $=0.090$ ). However, in absolute terms the strong group only moderately gets more than the weak group.

${ }^{18}$ A Mann-Whitney test reveals significant differences between the shares allocated to the strong group in the treatments with 3-0 composition. This holds for the unanimity rule (p-value $<0.001$ ) and for the majority rule $(\mathrm{p}$-value $=0.025)$ as well.
} 
allocate less than 9 Euros to the weak group in U21. In M21, where the weak group is represented in the decision committee but has no veto power, allocations of zero to members of the weak group occur but are much less frequent than allocations above five Euro. Notably, in the treatments where the weak group is not represented, the most frequent allocation to the weak group is 0 Euro (see U30 and M30).

Now consider the distributions of offers to the strong group (see the four graphs on the right in Figure 3). We observe that in U21 and M21 an offer of 14 Euro to members of the strong group is most prominent among all possible offers. Note that this offer is part of the division that is most closest to an equal division of the money on the table (14 Euro per recipient and 16 for the proposer). We find that the pattern of offers does not significantly differ between U21 and M21. ${ }^{19}$ In the treatments without representation of the weak group in the decision committee the picture is more diverse. Thus, the distributions of shares allocated to the strong group in U21 and M21 significantly differs from all distributions in the other treatments. ${ }^{20}$ The only exception is the comparison of M21 and U30, where we do not observe a significant difference. ${ }^{21}$ A second interesting observation is that in the treatments with majority voting offers are less concentrated. Both, in M21 and M30, they reach up to $25 \%$ of the pie per person for members of the strong group. In those cases the proposer obviously intends to share the pie equally among herself and the three members of the strong group (25\% each). Overall, the analysis of proposals reveals that in U21 proposers have substantially more homogenous views on what is an adequate offer.

We summarize our findings in Result 1. Note that parts (i) and (ii) of the result are in line with our Hypothesis 1.

\section{RESUlt 1 (Proposals)}

(i) Proposers on average claim more for themselves than they award to recipients. In U21, where both groups have veto power proposer claims are more moderate (27\% on average) than in all other treatments (roughly $35 \%$ on average).

(ii) Equal division of the pie among the weak and the strong group is observed only if both groups have veto power (i.e., when both groups are represented in the decision committee and the unanimity rule applies).

(iii) Members of the weak group are offered a significantly lower share if the weak group has no veto power (i.e. in U30, M21, and M30). They are offered the lowest shares if they are not represented in the decision committee at all.

(iv) Members of the strong group are offered significantly more if members of the weak group are not represented in the decision committee.

\footnotetext{
${ }^{19}$ Kolmogorov Smirnov test, p-value $=0.310$.

${ }^{20}$ Kolmogorov Smirnov tests reveal highly significant differences between the distributions in U21 and U30 (p-value $<0.001$ ), U21 and M30 (p-value < 0.001), and a significant difference for: M21 and M30 (p-value =0.055).

${ }^{21}$ Kolmogorov Smirnov test, $\mathrm{p}$-value $=0.139$.
} 


\subsection{Responder Behavior}

In this section we analyze individual and collective response behavior, acceptance rates (i.e. efficiency), as well as the final distribution of payoffs. Figure 4 gives a first impression of the acceptance rates as well as average payoffs obtained by the proposer and the members of the weak and strong groups.

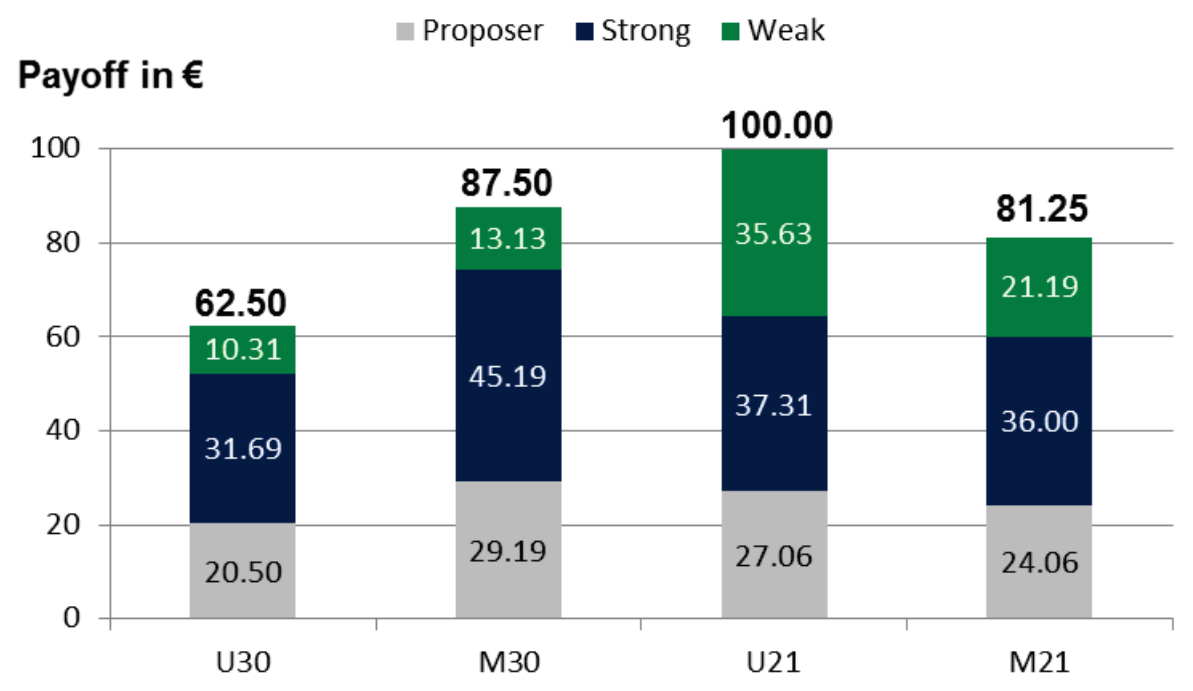

Figure 4: Efficiency and Realized Payoff Distribution. Payoffs are presented at the group level.

Most notably, only in treatment U21 all proposals are accepted by the decision committee. The lowest acceptance rate is observed in U30. Here, only $62.5 \%$ of the proposals are accepted. We thus find that representation of the weak group in the decision committee (in U21) leads to substantially higher acceptance rates if unanimity is required in the decision making process as compared to U30. ${ }^{22}$

The two treatments with majority rule have intermediate acceptance rates which are not significantly different. ${ }^{23}$ However, it turns out that in M21 significantly less proposals are accepted than in U21. ${ }^{24}$ At the first glance this is surprising: In M21 a proposal only has to get two out of three votes, whereas in U21 it has to receive unanimous support. Note, however, that a proposer who is aware of this makes substantially different proposals (see last section), which explains the difference in acceptance rates between U21 and M21. We will later provide some further evidence on the causes of those very different acceptance rates across treatments.

The average realized payoffs per group as indicated in the bars in Figure 4 show the same patterns as the proposed distributions described in section 5.1. Proposers generally get the largest share among all seven agents. Except for treatment U21 members of the strong group receive substantially more than members of the weak group. Note that average payoffs as stated in Figure 4 include groups

\footnotetext{
${ }^{22} \mathrm{Chi}^{2}$ test: $\chi^{2}(1)=14.77(\mathrm{p}$-value $<0.001)$.

${ }^{23} \mathrm{Chi}^{2}$ test: $\chi^{2}(1)=1.659(\mathrm{p}$-value $=0.198)$.

${ }^{24} \mathrm{Chi}^{2}$ test: $\chi^{2}(1)=6.62(\mathrm{p}$-value $=0.010)$. There is no significant difference when comparing U21 and M30: Chi ${ }^{2}$ test: $\chi^{2}(1)=0.67(\mathrm{p}$-value $=0.414)$.
} 
with rejected offers where all participants earn zero, which explains that some values are substantially lower than those in Figure 3. The order of proposer shares across treatments is partly turned around (as compared to the average shares proposed) due to different rejections rates across treatments. In two of the treatments where we observed rejections (U30 and M21) average realized proposer payoffs are significantly lower than average claims by the proposers. ${ }^{25}$ The same holds for the average share received by the strong group ${ }^{26}$ the weak group, ${ }^{27}$ where the order of average payoffs received is the same as the order of average shares proposed.

When we consider realized average payoffs, representation in the committee seems to be an important factor. The group of weak players earns the lowest expected average payoffs if they are not represented in the responder group. They receive the highest average payoff (35.63 Euros) if they have credible veto power (U21), ${ }^{28}$ and an intermediate average payoff in M21 (21.19 Euros), where they are represented but have no veto power.

\begin{tabular}{lcccc}
\hline \hline Treatment & Decision & Proposer & Strong & Weak \\
\hline \multirow{2}{*}{ U21 } & Accept & 27.06 & 37.31 & 35.63 \\
& Reject & 27.06 & 37.31 & 35.63 \\
\hline \multirow{2}{*}{ M21 } & Accept & 29.61 & 44.30 & 26.08 \\
& Reject & 52.00 & 32.00 & 16.00 \\
\hline \multirow{2}{*}{ U30 } & Accept & 32.80 & 50.70 & 16.50 \\
& Reject & 38.50 & 45.50 & 16.00 \\
\hline \multirow{2}{*}{ M30 } & Accept & 33.36 & 51.64 & 15.00 \\
& Reject & 50.50 & 33.00 & 16.50 \\
\hline \hline
\end{tabular}

Table 2: Accepted and rejected proposals of members of the strong/weak group (average divisions).

Table 2 and Figure 5 yield some further insights with respect to the reasons for rejection of proposals. The Table provides average divisions of the pie separately for accepted and rejected proposals. In M21 and M30 rejected proposals exhibit an average proposer share of more than Euro 50, whereas the average proposer share of accepted proposals ranges around Euro 30. This clearly indicates that excessive claims by the proposer are a key reason for rejection. Note that in both cases the strong group alone has the power to accept the proposal and representatives of the strong group forego on average more than 10 Euros in order to punish excessive claims by the proposer. Whereas in M30, where the weak group is not represented in the decision committee, the share of the weak group is similar across accepted and rejected proposal, this is not the case in M21, where the weak group is represented. Here a too low share for the weak group seems to trigger rejection, which again points to the importance of representation.

In U30 the picture is less clear. Average proposer shares of rejected proposals are only slightly higher than those of accepted ones (Euro 38.50 vs. Euro 32.80). Given that in U30 we observed

\footnotetext{
${ }^{25}$ Wilcoxon-Matched Pairs show significant differences for U30 (claimed share: 34.94 ; payoff: 20.50; p-value =0.015) and M21 (claimed share: 33.81; payoff: 24.06; p-value $=0.084$ ). Proposer shares are not significantly lower in M30 (claimed share: 35.50; payoff: 29.19; p-value $=0.158)$.

${ }^{26}$ Wilcoxon-Matched Pairs test, p-value 0.015 (U30); p-value $=0.084(\mathrm{M} 21)$.

${ }^{27}$ Wilcoxon-Matched Pairs test, p-value $=0.046(\mathrm{U} 30) ; \mathrm{p}$-value $=0.084(\mathrm{M} 21)$.

${ }^{28}$ Mann-Whitney test, $\mathrm{p}<0.001$ (U21 vs. U30); $\mathrm{p}<0.001$ (U21 vs. M30); $\mathrm{p}$-value $=0.014$ (U21 vs. M21).
} 
the highest number of rejections it is worthwhile to look at the data in more detail. Figure 5 gives a holistic impression of the bargaining process: The $\mathrm{x}$-axis denotes the proposer share, on the $\mathrm{y}$ axis we feature the quotient of the share proposed to the weak group divided through the share proposed to the strong group ( 1 is equal division, a value of 0 indicates that the weak group receives nothing). Green dots represent accepted proposals (bigger dots indicate higher frequency), each red square represents a rejected proposal. The picture clearly confirms the intuition that a high proposer share is the main trigger for rejections in M21 and M30. In U30 we find a more diverse picture: Committee members reject all kinds of proposals. These are proposer shares of over Euro 50 (two times), proposals that do not offer a positive share to members of the weak group (three times), but also those where the proposer claims a low amount for herself but offers equal share to members of the strong and the weak groups (two times). Note that any rejection costs the rejecting agent more than 10 Euros. Obviously, agents severely disagree how an adequate proposal in U30 should look like. Violation of desirable attributes could be provoked by (i) too high proposer shares, (ii) a too low share for the weak group, or even (iii) a too high share for the weak group. The high rejection rates in $\mathrm{U} 30$ seem to be due to normative uncertainty.

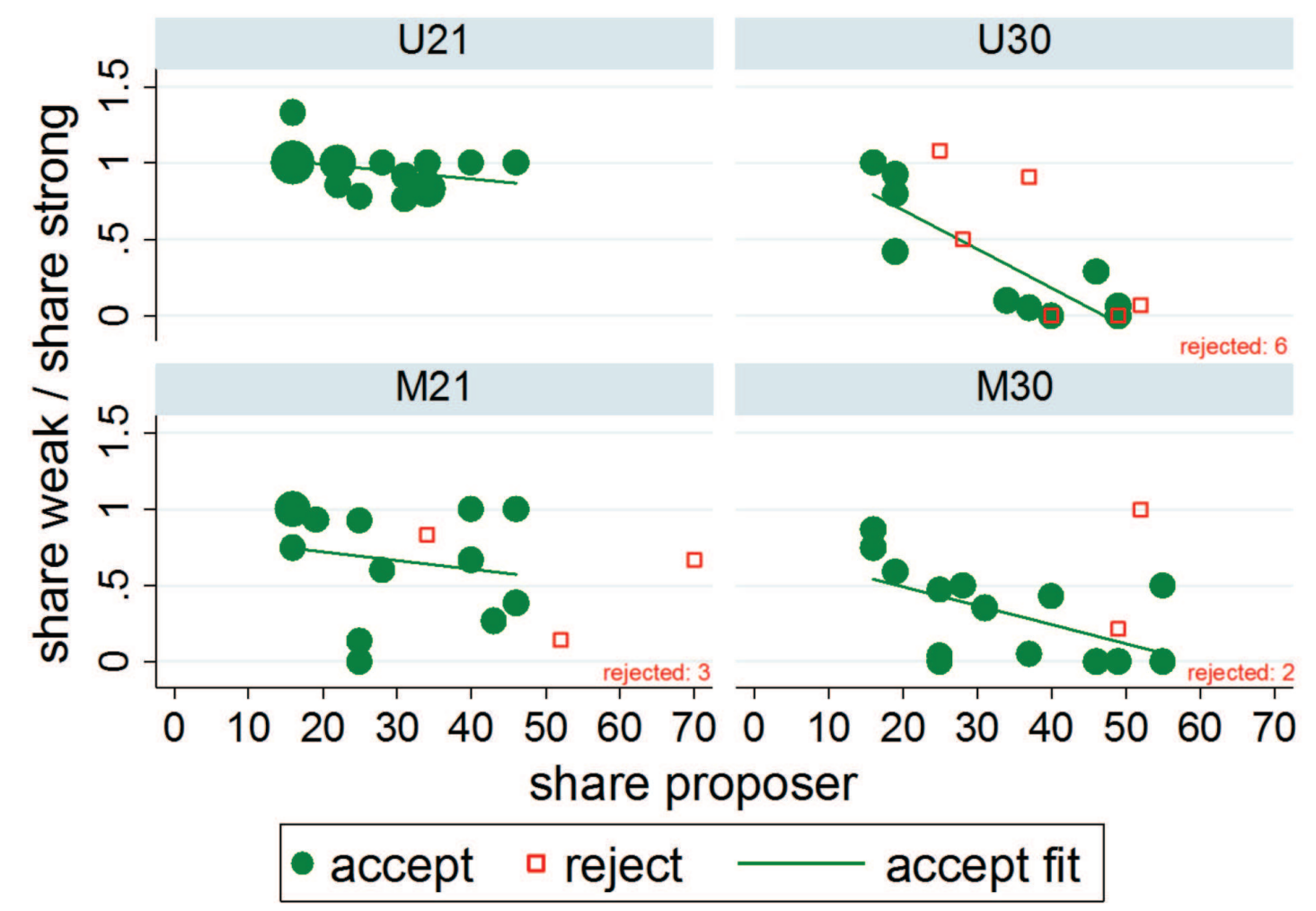

Figure 5: Accepted and rejected proposals conditioned on the shares proposed to the weak/strong group.

Finally, Figure 5 nicely illustrates that also the nature of proposals in the different treatments contributes to understanding the high acceptance rate in treatment U21. Obviously, anticipation of 
a collective decision under the unanimity rule among representatives of both groups implies clear guidelines what a sensible proposal should look like. All proposals award equal shares to both groups and no proposer claims more than $50 \%$ of the pie, most of them less than 40\%. In U30 and M30, where the weak group is not represented in the decision committee, only few proposers choose equal proportions. The majority of proposers choose asymmetric proportions.

\begin{tabular}{|c|c|c|c|}
\hline & \multicolumn{3}{|c|}{ "acceptance of proposals } \\
\hline & $(1)$ & $(2)$ & $(3)$ \\
\hline U30 & $\begin{array}{c}-4.616^{* * *} \\
(0.205)\end{array}$ & $\begin{array}{c}-5.506^{* * * *} \\
(0.625)\end{array}$ & $\begin{array}{c}-5.571^{* * *} \\
(0.348)\end{array}$ \\
\hline M21 & $\begin{array}{c}-5.218^{* * *} \\
(0.250)\end{array}$ & $\begin{array}{c}-5.612^{* * *} \\
(0.474)\end{array}$ & $\begin{array}{c}-5.413^{* * *} \\
(0.431)\end{array}$ \\
\hline M30 & $\begin{array}{c}-4.616^{* * *} \\
(0.290)\end{array}$ & $\begin{array}{c}-5.408^{* * * *} \\
(0.598)\end{array}$ & $\begin{array}{c}-5.482^{* * *} \\
(0.375)\end{array}$ \\
\hline proposer share & & $\begin{array}{c}-0.054^{* * *} \\
(0.012)\end{array}$ & $\begin{array}{c}-0.065^{* * *} \\
(0.011)\end{array}$ \\
\hline female responder & & $\begin{array}{c}0.730^{* *} \\
(0.351)\end{array}$ & $\begin{array}{c}1.012^{* *} \\
(0.410)\end{array}$ \\
\hline weak group & & $\begin{array}{c}-1.254^{* * *} \\
(0.483)\end{array}$ & $\begin{array}{c}-4.296^{* * *} \\
(1.232)\end{array}$ \\
\hline share weak/share strong & & $\begin{array}{l}-0.350 \\
(0.453)\end{array}$ & $\begin{array}{c}-1.098^{* * *} \\
(0.322)\end{array}$ \\
\hline weak group $\times$ share weak/share strong & & & $\begin{array}{c}4.730^{* * *} \\
(1.428)\end{array}$ \\
\hline constant & $\begin{array}{c}5.767^{* * * *} \\
(0.058)\end{array}$ & $\begin{array}{c}8.532^{* * * *} \\
(0.935)\end{array}$ & $\begin{array}{c}9.208^{* * *} \\
(0.652)\end{array}$ \\
\hline Pseudo $R^{2}$ & 0.144 & 0.365 & 0.452 \\
\hline observations & 192 & 192 & 192 \\
\hline
\end{tabular}

Robust standard errors in parentheses *** $\mathrm{p}<0.01,{ }^{* *} \mathrm{p}<0.05,{ }^{*} \mathrm{p}<0.1$

Table 3: Probit regressions on the acceptance of proposals. The regressions are clustered on the matching group level. Standard errors in parentheses.

To get some additional insights about the responders' motives of accepting/rejecting proposals, we run probit regressions with the likelihood of acceptance as a dependent variable. The regressions take into account individual decisions of all responders of the strong and weak group and are clustered at the group level for 64 independent groups. We use U21 as a baseline and include dummies for U30, M21, and M30. As explanatory variables we include proposer share which allows to analyze the impact of the proposer share on responders' likelihood to accept proposals. The model moreover incorporates a dummy for the responder gender (female responder), which indicates whether a responder is female. Another dummy is weak group which indicates whether the responder is a member of the weak group. share weak/share strong is a ratio measuring the inequity of proposals between 
the strong and the weak group. Finally, weak group $\times$ share weak/share strong is the interaction of weak group and share weak/share strong.

Regression (1) shows that the acceptance of proposals is significantly lower in U30, M21 and M30 compared to U21. Regression (2) shows that proposer share is highly significant with a negative sign, i.e., proposers claiming high shares face a significantly lower likelihood of acceptance by responders. Moreover, female responders accept proposals more likely than men. We find that weak group is significant and negative, i.e., responders who are members of the weak group are less likely to accept proposals. Finally, Regression (3) shows that members of the weak group are more likely to accept proposals when the ratio: share weak group/share strong group is high.

\section{Result 2 (Acceptance Rates, Efficiency, and Payoffs)}

(i) In U21 (unanimity and veto power of both groups) proposals are never rejected. Rejection rates are highest in U30 (unanimity rule and no weak group-members are represented in the decision committee), and intermediate in the treatments where decisions are taken by the majority rule.

(ii) Rejections mainly occur if the share that the proposer claims is too high. In U30 rejections are also triggered if (i) responders perceive the share of the weak group being too low or (ii) responders perceive the share of the weak group inadequately high.

(iii) Proposals are rejected more likely by male responders and representatives of the weak group in the decision committee.

Note that parts (i) and (ii) of the result are very much in line with our Hypothesis 2. It is particularly interesting that rejection rates are highest in U30, where unanimity is required but the weak group is not represented in the decision committee. Here, theory predicts that responders showing a different degree of inequality aversion would consider very different proposals as adequate. Thus, under uncertainty about the inequality aversion of responders it would be impossible to make a proposal that is accepted with probability one - thus, high rejection rates should be expected (Hypothesis 2). Altogether, our findings in sections 5.1 and 5.2 reflect the consideration made in section 4 very nicely, suggesting that inequality aversion is a main driver of decision making behavior in our setup. It is worth emphasizing that the institutional frame (decision rule and representation of groups) has a clear impact on proposals. In particular, the nature of proposals made clearly suggests that proposers reason about the consequences of their actions. Since one central insight is that heterogeneity of social preferences combined with incomplete information might be a main driver of high rejection rates in some treatments, we take a closer look at how the induced inefficiencies are affected by the possibility of ex ante (non-binding) communication.

\subsection{The Impact of Communication}

In a second set of experiments we ran the same treatments, adding a five minute chat among the proposer and the members of the decision committee before the multi-person ultimatum game was 
played. Receivers did not participate in the chat. In extension of our original denominations we denote those additional treatments by CU21, CM21, CU30, and CM30.

During the five minute chat participants were given the opportunity to discuss the game in a chat window. They were clearly told in the instructions that they were not supposed to reveal information that pointed to their identity (e.g. name, field of study, gender etc.). When participants sent a message, their role (proposer or responder) and their group membership (green or blue) was reported. ${ }^{29}$ Table 5 compares the proposals allocated in the no communication treatments with the proposals in the communication treatments.

\begin{tabular}{lcccccc}
\hline \hline Role & Treatment & No Communication & Std. Dev. & Communication & Std. Dev. & Difference \\
\hline \multirow{5}{*}{ Proposer } & (C)U21 & 27.06 & 9.21 & 16.00 & 0.00 & 11.06 \\
& (C)M21 & 33.81 & 15.35 & 19.38 & 3.74 & 14.43 \\
& (C)U30 & 34.94 & 12.48 & 22.33 & 3.50 & 12.61 \\
& (C)M30 & 35.50 & 14.07 & 24.25 & 7.13 & 11.25 \\
\hline \multirow{5}{*}{ Strong Group } & CU21 & 12.44 & 1.50 & 14.00 & 0.00 & 1.56 \\
& (C)M21 & 14.00 & 4.52 & 15.75 & 3.49 & 1.75 \\
& (C)U30 & 16.25 & 2.93 & 19.67 & 4.92 & 3.42 \\
& (C)M30 & 16.44 & 4.29 & 19.00 & 3.65 & 2.56 \\
\hline \multirow{5}{*}{ Weak Group } & CU21 & 11.88 & 1.96 & 14.00 & 0.00 & 2.12 \\
& (C)M21 & 8.06 & 4.51 & 11.13 & 4.13 & 3.07 \\
& (C)U30 & 5.44 & 5.51 & 6.22 & 5.47 & 0.78 \\
& (C)M30 & 5.06 & 4.46 & 6.25 & 5.02 & 1.19 \\
\hline \hline
\end{tabular}

Table 4: Proposals with and without a upfront communication.

A first glimpse at the data reveals that in presence of the communication opportunity, (i) the order of proposer shares and blue/green group shares is maintained, (ii) the proposers claim less for themselves in all treatments and (iii) distribute additional "free" money to groups represented in the decision committee, and finally (iv) the heterogeneity of proposals decreases remarkably.

Let us come back to those issues in more detail: Obviously, with the communication opportunity the order of proposals allocated to the proposers and members of the strong/weak group is maintained. That is, proposers claim the highest share in CM30 and the lowest share in CU21. Again, if the weak group is not represented in the decision committee, the proposers claim more than if it is represented. The order also is maintained for the strong group which is offered the smallest share in CU21 and the highest shares in CU30 and CM30. As a consequence members of the weak group receive the highest shares in CU21 and the lowest share in CM30.

In all treatments we clearly observe level effects: With a communication opportunity the proposer claims significantly less for herself as compared to the non-communication treatments. ${ }^{30}$ The effect is substantial, i.e. around 10 percentage points in all treatments. The money is distributed mainly among those groups that have representatives in the chat, even if the respective group has no veto

\footnotetext{
${ }^{29}$ This was done by using neutral names, e.g., the prefixes "Responder_green_A" or "Responder_blue_B" were used.

${ }^{30}$ All differences are significant at least at the $5 \%$ level for two tailed Mann-Whitney tests. The difference between M30 and CM30 is weakly significant at the $10 \%$ level.
} 
power. This is impressively illustrated if one compares the differences reported in the last column of Table 4: In CU21 the share of the weak group raises by more than two percentage points, CM21 (where the weak group does not even have veto power) it raises even by 3 percentage points as compared to the treatments without ex ante communication. In the treatments without representation of the weak group the effect is only around 1 percentage point. In those treatments (CU30 and CM30) the money that is not claimed by the proposer (as compared to the setting without communication) clearly is distributed among the members of the strong group - which is the only group represented in the decision committee. This evidence again suggests that representation is important, even if it just means to have a voice but not veto power. Note that in our setup the effect cannot be caused by anticipation of future interaction with the representatives of the weak group — which might actually intensify the effect in a real life setting.

Let us finally address responder behavior. We find that in the presence of communication all proposals are accepted. This is certainly due to the fact that communication leads to much more balanced and less heterogeneous proposals. First, communication can contribute to a better match between the proposals and the normative views of the members of the committee, and second, the committee members will learn about the concerns of their fellow responders in the ex ante communication and can intervene and persuade others if they strongly object to something. Interestingly, proposals made after exchanging views in a communication stage look surprisingly similar across all groups, see Figure 6.

We summarize our findings in the following result:

\section{RESUlT 3 (The Impact of Communication)}

(i) The order of proposals in the four treatments is not affected by the communication opportunity. Proposers claim most for themselves in CM30 and least in CU21, and they claim less if the weak group is represented than if it is not.

(ii) Proposers claim more than 10 percentage points less for themselves in the presence of the communication opportunity in all treatments.

(iii) The money not claimed by the proposer is distributed mainly among the groups that are represented in the decision committee (and therefore participate in the chat). If the weak group is not represented, the increase in shares is insignificant.

(iv) In the presence of an upfront communication opportunity all proposals are accepted.

\subsection{The Content of Communication}

To better understand the substantial effect of communication on negotiation outcomes, we take a closer look at the content of the chat protocols in this section. Table 5 provides a categorization of 


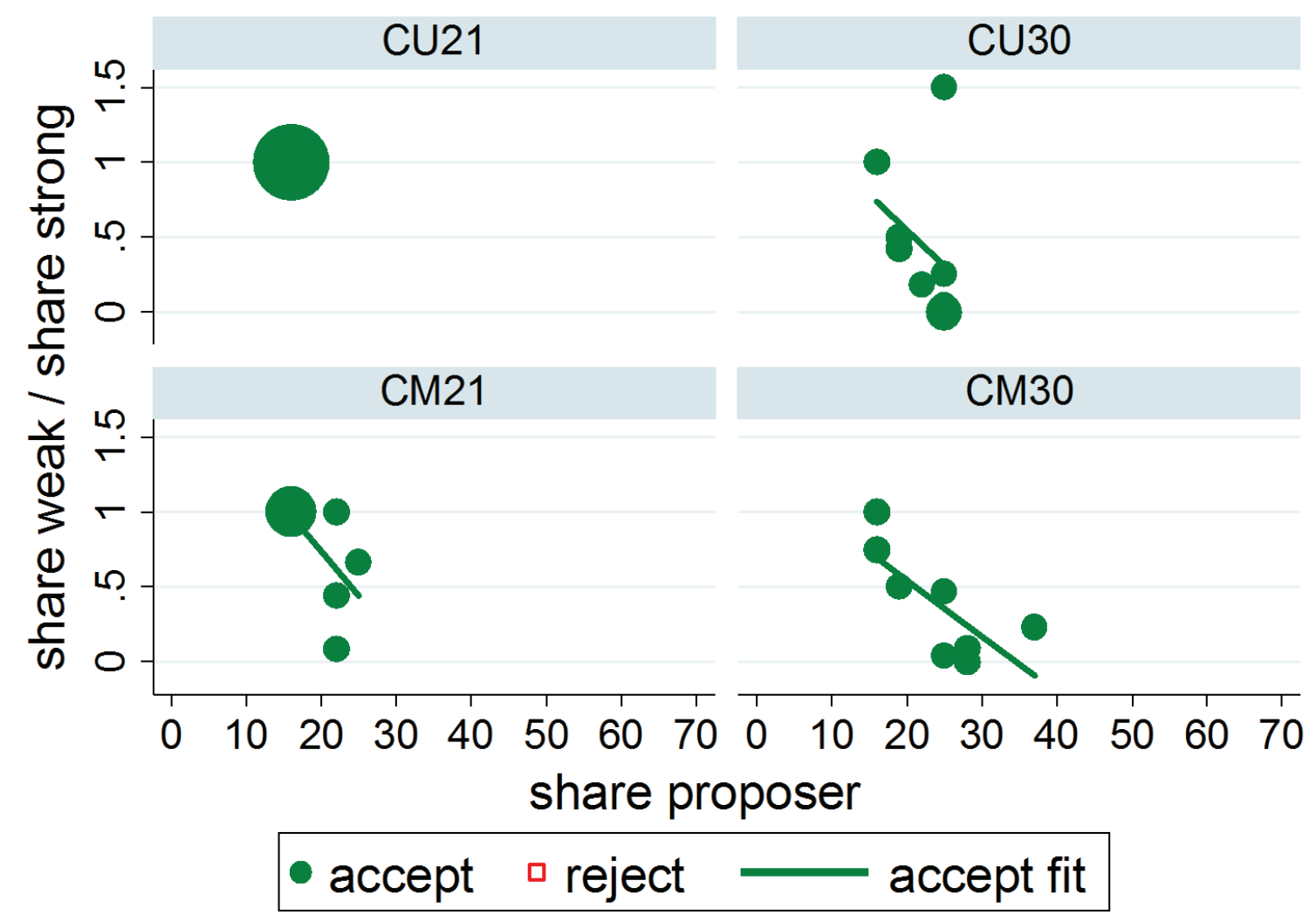

Figure 6: Accepted and rejected proposals conditioned on the shares proposed to the weak/strong group, treatments with ex ante communication

the messages sent in our different treatments and yields some interesting insights with respect to the content of communication. ${ }^{31}$

The first column reports the average number of messages sent by participants in a certain role in our different treatments. We observe that proposers contribute less in CU21 than in all other treatments, whereas responders contribute more or less equally across roles and treatments. In CM30 the average number of messages is highest among proposers and responders. ${ }^{32}$

The last four columns report in how many interaction groups (i.e. in how many of the 5-minute chat conversations between proposer and responders) the following proposals were made:

(i) Equal Split: choose the most equal distribution possible $(16,14,14)$,

(ii) Equal Among Groups: treat the groups equally, but probably worse than the proposer,

(iii) Unequal Split: treat one group worse than the other and give the proposer more than 16.

(iv) Threat: announcement not to accept the proposal if one's suggestion was not followed.

\footnotetext{
${ }^{31}$ Similar to e.g. Falk and Kosfeld (2006) and Andersen and Wengström (2007) we find that categorized content can be helpful to understand subjects' motives as well as the role of communication.

${ }^{32}$ After reaching an agreement subjects often started to discuss completely different things than the experiment. Elimination of the unrelated parts of the conversations leads to lower absolute numbers, but the same proportions.
} 


\begin{tabular}{|c|c|c|c|c|c|c|}
\hline & & $\overline{(1)}$ & $\overline{(2)}$ & $\overline{(\overline{(3)})}$ & $\overline{(4)}$ & $\overline{(5)}$ \\
\hline Treatment & Role & $\begin{array}{c}\text { Avg. \# of } \\
\text { messages } \\
\text { sent }\end{array}$ & $\begin{array}{l}\text { Equal } \\
\text { Split }\end{array}$ & $\begin{array}{l}\text { Equal } \\
\text { Among } \\
\text { Groups }\end{array}$ & $\begin{array}{c}\text { Unequal } \\
\text { Split }\end{array}$ & Threat \\
\hline \multirow{3}{*}{ CU21 } & Proposer & 7.00 & $77.8 \%$ & $37.5 \%$ & $33.3 \%$ & $11.1 \%$ \\
\hline & Strong & 6.94 & $77.8 \%$ & $0.0 \%$ & $11.1 \%$ & $11.1 \%$ \\
\hline & Weak & 7.11 & $44.4 \%$ & $0.0 \%$ & $0.0 \%$ & $33.3 \%$ \\
\hline \multirow{3}{*}{ CM21 } & Proposer & 9.38 & $37.5 \%$ & $12.5 \%$ & $25.0 \%$ & $0.0 \%$ \\
\hline & Strong & 6.25 & $62.5 \%$ & $12.5 \%$ & $50.0 \%$ & $12.50 \%$ \\
\hline & Weak & 7.38 & $62.5 \%$ & $37.5 \%$ & $0.0 \%$ & $25.0 \%$ \\
\hline \multirow{2}{*}{ CU30 } & Proposer & 9.88 & $11.1 \%$ & $0.0 \%$ & $77.8 \%$ & $0.0 \%$ \\
\hline & Strong & 7.33 & $11.1 \%$ & $0.0 \%$ & $77.8 \%$ & $22.2 \%$ \\
\hline \multirow{2}{*}{ CM30 } & Propo & 11.38 & $0.0 \%$ & $0.0 \%$ & $87.5 \%$ & $12.5 \%$ \\
\hline & Strong & 9.79 & $37.5 \%$ & $25.0 \%$ & $75.0 \%$ & $37.5 \%$ \\
\hline
\end{tabular}

Table 5: Average number of messages sent in the 5-minute chat per person by treatment and role (column (1)) and suggested properties of proposals (columns (2) to (5)). Each percentage refers to the share of conversations (i.e. 5-minute chats) in which the respective suggestion occurred.

The table corresponds nicely to the behavioral data. In those treatments where we observed rejection rates without communication (CM21, CU30, and CM30) we see more activity in the chat. An equal split is asked predominantly if both groups are represented. A split where the proposer gets more than the equal share but groups are treated similarly is suggested by members of the weak group in M21, where they participate in the chat but have no veto power when it comes to a decision. Unequal splits are predominantly suggested in those conversations where the weak group does not participate (30-treatments). Threats are used by 20 to 30 percent of the members of the weak group if they participate in the conversation (in which case members of the strong group do not use threats) and by members of the strong group in those treatments where weak group members do not participate. In appendix A.2 we provide some examples of representative chat protocols.

This section has revealed that communication seems to work as powerful coordination device. Coordination leads to the most equal outcome in all groups in CU21 where participants most often explicitly mention the fair allocation, whereas unfair allocations are discussed least often. In contrast, participants most often discuss unfair allocations if the weak group is not present and if decisions are made by majority rule.

\section{RESUlT 4 (The Content of Communication)}

(i) Proposers contribute less to the chat in U21 than in all other treatments.

(ii) The Equal Split is predominantly suggested if the weak group participates in the chat.

(iii) An Unequal Split is suggested by the vast majority of participants if the weak group does not participate in the chat.

(iv) Threats are used by 20 to 30 percent of the weakest group in the chat. 


\section{Conclusion}

In this paper we have analyzed multi-person ultimatum bargaining games that in a stylized way capture key elements of collective bargaining procedures. In our setup a single proposer makes an offer how to divide a pie among herself and six recipients that are divided into two groups - a weak and a strong group. The offers are restricted to allocate the same amount to each member of the same group (weak or strong). Offers are decided upon by a decision committee that comprises either of three representatives of the strong group or of two representatives of the strong group and one from the weak group. In a 2x2 factorial design we vary (i) the composition of the decision committee and (ii) the decision rule within the decision committee (either unanimity or majority voting).

We find that proposers generally claim a large part of the pie for themselves (around 30\%). Claims are more moderate only if both groups have decision power, i.e., in the case both are represented in the decision committee and unanimity is required for acceptance. This is also the only treatment where proposals grant roughly equal shares to both groups. In all other treatments, the weak group receives significantly lower offers than the strong group. Representation in the decision committee, however, matters also in the absence of veto power: Offers to the weak groups are lowest (and often zero) if they are not represented at all. Acceptance rates vary in a surprising way across treatments: Proposals are always accepted in the treatment where all groups have veto power. Recall that in this case proposer claims are moderate, and offers to both groups are almost equal. Moreover we do not observe a lot of heterogeneity across offers, which suggests that the setup gives clear guidance what an adequate proposal looks like. The lowest acceptance rates are observed in the treatment where the decision committee is composed of only members of the strong group and unanimity is required. In this case proposals differ a lot: some proposers suggest equal shares for the strong and the weak group, some do not considers the weak group at al; some make moderate claims, some claim even more than 50\%. Roughly $40 \%$ of those proposals are rejected, for a variety of reasons: too high claims of the proper, bad treatment of the weak group, but also high shares of the weak group trigger rejections. Obviously, in this treatment there is no common view on how proposals should look like. Rejection rates in the treatments with majority voting range somewhere in between (15-20\%). This is presumably due to the fact that the proposal has to convince only two out of the three members of the committee.

In a second set of experiments we repeat our treatment with the possibility of non-binding communication among the proposer and the members of the decision committee upfront. Communication has clear and strong effects: Proposer shares decrease, while the share of groups increase that are represented in the decision committee (and thus in the chat). Shares of groups not represented in the chat are hardly effected. Heterogeneity of proposals decreases substantially. In the treatment where all groups are represented and unanimity is required all nine proposers even make exactly the same proposal! We observe no rejections in any treatment which strongly emphasizes the efficiency enhancing effect of (non-binding) communication.

Let us finally draw our attention to gender specific behavior. In order to be able to look at 
gender effects we recruited equal proportions of male and female participants and assigned equal proportions of men and women to each role in our experiment. We do not observe differences in proposer behavior ${ }^{33}$ However, we find that female responders are more likely to accept a proposal than men. Remember that in our design there was no gender specific information given to the participants so they could not be identified as male or female and get systematically different offers for this reason. In an extension of our design we consider the case where gender can be identified and observe more gender specific effects, which may give rise to a gender wage gap. ${ }^{34}$ As Azmat and Petrongola (2014) recently emphasized, experimental evidence on gender effects at the team level where group composition is determined exogenously is still relatively scarce. An extension of our setting to open gender information bargaining games should thus be a next step in the research agenda.

How do our experiments reconcile with real world bargaining, as in collective wage negotiations? In interviews, experts pointed out that worker groups disposition to strike is more important for their outcomes than direct representation in committees (Gärtner et al., 2015). This is not at odds with our finding that in a stylized bargaining game workers representation in committees is crucial for their share in the pie. It merely hints to the fact that bargaining power can be obtained either by direct representation or by indirect exertion of influence. Nonetheless, if society strives to improve the situation of groups that are missing even indirect influence, the introduction of quotas in decision committees would be an adequate approach. Furthermore, our results suggest that informal upfront communication prior to formal wage negotiations serves an important economic function: These meetings seem to drastically decrease the risk of offer rejections which in the real world might be equivalent to productivity reducing long-lasting industrial conflicts.

While our experiments are neutrally framed, our results can contribute to a better understanding of real world bargaining situations. For instance, while the gender wage gap is compressed in a unionized setting (e.g. Heinze and Wolf 2010), a gender wage gap still remains. Consequently, there has been a long term discussion how professions with a high share of female workers should be represented in collective wage negotiations, and if quotas can contribute to gender equality in bargaining (Briskin 2014, Heery 2006, Kirsch and Blaschke 2014). While there have been some attempts to look into the black box of collective wage negotiations using qualitative methods (Gärtner et al. 2015, Kirsch and Blaschke 2014), these methods cannot uncover causal relationships between bargaining structures and outcomes. Our results lend some causal support to the hypotheses that quotas (and thus, representation) could have an impact on economic outcomes and that informal communication among negotiation partners plays an important role in ensuring efficiency.

\footnotetext{
${ }^{33}$ Male proposers claim (up to 10 percentage points) more for themselves in all treatments but the effect is not significant. We wonder whether this is due to little statistical power that we find nothing, since the number of observations per treatment is halved.

${ }^{34}$ Grimm et. al., work in progress.
} 


\section{References}

[1] Alós-Ferrer, C., and Kuzmics, C., 2013, Hidden symmetries and focal points. Journal of Economic Theory, 148, 226-258.

[2] Andersson, O. and Wengström, E., 2007, Do Antitrust Laws Facilitate Collusion? Experimental Evidence on Costly Communication in Duopolies. Scandinavian Journal of Economics, 109, 321-339.

[3] Azmat, G., Petrongola, B., 2014, Gender and the labor market: What have we learned from field and lab experiments? Labour Economics, 30, 32-40.

[4] Bearden, J.N. 2001, Ultimatum bargaining experiments: The state of the art. Available at SSRN 626183.

[5] Bereby-Meyer, Y., and Niederle, M., 2005, Fairness in bargaining. Journal of Economic Behavior and Organization, 56, 173-186.

[6] Bornstein, G. and Yaniv, I., 1998, Individual and Group Behavior in the Ultimatum Game: Are Groups More Rational Players? Experimental Economics, 1, 101-108.

[7] Blanco, M., Engelmann, D., Normann, H.T., 2011, A within-subject analysis of other-regarding preferences. Games and Economic Behavior, 72, 321-338.

[8] Briskin, L., 2014, Strategies to support equality bargaining inside unions: Representational democracy and representational justice. Journal of Industrial Relations, 56, 208-227.

[9] Cameron, L.A., 1999, Raising the stakes in the ultimatum game: Evidence from Indonesia. Journal of Economic Inquiry, 37, 47-59.

[10] Cason, T. N., and Mui, V. L., 1997, A laboratory study of group polarisation in the team dictator game. The Economic Journal, 107, 1465-1483.

[11] Charness, G. and Dufwenberg, M., 2006, Promises and Partnership. Econometrica, 74, 15791601.

[12] Cooper, R., DeJong, D.V., Forsythe and Ross, T. W., 1989, Communication in the Battle of the Sexes Game: Some Experimental Results. RAND Journal of Economics, 20, 568-587.

[13] Cooper, R., DeJong, D.V., Forsythe and Ross, T. W., 1992, Communication in Coordination Games. Quarterley Journal of Economics, 107, 739-771.

[14] Cooper, D. J., Kagel, J. H., 2005, Are two heads better than one? Team versus individual play in signaling games. American Economic Review, 95, 477-509. 
[15] Cooper, D.J., Kühn, K.U., 2014, Communication, renegotiation, and the scope for collusion, American Economic Journal: Microeconomics, 6, 247-278.

[16] Dufwenberg, M., and Muren, A., 2006, Generosity, anonymity, gender. Journal of Economic Behavior \& Organization, 61, 42-49.

[17] Falk, A. and Kosfeld, M., 2006, The hidden costs of control. American Economic Review, 96, 1611-1630.

[18] Fehr, E. and Schmidt, K. M., 1999, A Theory of Fairness, Competition, and Cooperation. Quarterly Journal of Economics, 114, 817-868.

[19] Fischbacher, U., 2007, z-Tree: Zurich toolbox for ready-made economic experiments. Experimental economics, 10, 171-178.

[20] Fonseca, M. and Normann, H.T., 2012, Explicit vs. tacit collusion - The impact of communication in oligopoly experiments. European Economic Review, 56, 1759-1772.

[21] Forsythe, R., Horowitz, J. L., Savin and Sefton, M., 1994, Fairness in Simple Bargaining Experiments. Games and Economic Behavior, 6, 347-369.

[22] Gärtner, D., Grimm, V., Lang, J., Stephan, G., 2015, Kollektive Lohnverhandlungen und der Gender Wage Gap - Befunde aus einer qualitativen Studie. Industrielle Beziehungen, 22, 260281.

[23] Greiner, B., 2004, An online recruitment system for economic experiments.

[24] Güth, W., Schmittberger R. and Schwarze, B., 1982, An Experimental Analysis of Ultimatum Bargaining. Journal of Economic Behavior \& Organization, 3, 367-388.

[25] Güth, W. and van Damme, E., 1998, Information, Strategic Behavior, and Fairness in Ultimatum Bargaining: Experimental Study. Journal of Mathematical Psychology, 42, 227-247.

[26] Güth, W., Schmidt, C., and Sutter, M., 2007, Bargaining outside the laba newspaper experiment of a three person ultimatum game. The Economic Journal, 117, 449-469.

[27] Heery, E., 2006, Equality bargaining: where, who, why?. Gender, Work \& Organization, 13, $522-542$.

[28] Heinze, A., Wolf, E., 2010, The intra-firm gender wage gap: a new view on wage differentials based on linked employer-employee data. Journal of Population Economics, 23, 851879.

[29] Kagel, J. H., and Wolfe, K. W., 2001, Tests of fairness models based on equity considerations in a three-person ultimatum game. Experimental Economics, 4, 203-219. 
[30] Kahneman, D., Knetsch, J. L. and Thaler, 1986, R. H., Fairness and the Assumptions of Economics. Journal of Business, 59, 285-300.

[31] Kimbrough, E.O., Smith, V.L. and Wilson, B.J., 2008. Historical Property Rights, Sociality, and the Emergence of Impersonal Exchange in Long-Distance Trade. American Economic Review, 98, 1009-1039.

[32] Kirsch, A., Blaschke, D., 2014, Womens quotas and their effects: A comparison of Austrian and German trade unions. European Journal of Industrial Relations, online first, DOI: $10.1177 / 0959680113518231$.

[33] Knez, M. J. and Camerer, C. F., 1995, Outside Options and Social Comparison in Three-Player Ultimatum Game Experiments. Games and Economic Behavior, 10, 65-94.

[34] Kocher, M. G., and Sutter, M., 2005, The Decision Maker Matters: Individual Versus Group Behaviour in Experimental Beauty-Contest Games. The Economic Journal, 115, 200-223.

[35] Luhan, W. J., Kocher, M. G., and Sutter, M., 2009, Group polarization in the team dictator game reconsidered. Experimental Economics, 12, 26-41.

[36] Messick, D. M., Moore, D. A. and Bazerman, M. H., 1997, Ultimatum Bargaining with a Group: Underestimating the Importance of the Decision Rule. Organizational Behavior and Human Decision Processes, 69, 87-101.

[37] Riedl, A., and Vyrastekova, J., 2003, Responder behavior in three-person ultimatum game experiments. CentER for Economic Research discussion paper, Tilburg University.

[38] Robert, C., and Carnevale, P. J., 1997, Group choice in ultimatum bargaining. Organizational Behavior and Human Decision Processes, 72, 256-279. 


\section{A Appendix - For Online Publication}

\section{A.1 Proof of Proposition 1}

In order to analyze proposer behavior under uncertainty about the inequality aversion of the decision makers we need assumptions concerning the distribution of inequality aversion parameters. Throughout our analysis we consider decision makers with Fehr Schmidt (1999) preferences, where $\alpha$ and $\beta$ parameters vary across individuals. From the proposer's point of view this implies that he faces uncertainty concerning these parameters. For simplicity, we assume that inequality averse agents, while they dislike unfavorable inequality more than favorable inequality, they either feel strong (or not) about both, i.e. $\beta_{i}=s \alpha_{i}, \forall i$. Note that the ratio between $\alpha_{i}$ and $\beta_{i}$ is assumed to be the same for all agents. Furthermore, we assume that from the proposer's point of view $\alpha_{i}$ are independent random variables that are identically distributed across all recipients on $[0, \bar{\alpha}]$ with distribution $F(\alpha)$.

Part (i) In order to analyze the optimal share that the proposer should claim in the different treatments, consider her expected payoffs as given in equations (5), (6), and (7) in the main text. In order to prove part (i) of the proposition we have to consider the case that it is optimal not to propose a positive share for the weak group if this group has no veto power. This requirement implies an upper bound on the degree of inequality aversion that could be expected. In the following we first show that this requirement is not too restrictive.

To this aim, consider the preferences of one member $i$ of the decision committee with inequality aversion parameter $\alpha_{i}$. We ask in the following how intense $i$ 's inequality aversion has to be such that it is more beneficial for the proposer to distribute the money that she does not claim for herself equally among all recipients, as compared to distributing it only among the members of the strong group. The proposer's aim is to maximize the share $x_{p}$ she can claim such that the responder is just indifferent between acceptance and rejection. As outlined above, we analyze two options: Either she distributes $1-x_{p}$ equally among the three members of $i$ 's group. Then, $i$ ' utility is given by

$$
u_{i}\left(x_{p}, \frac{1-x_{p}}{3}, 0\right)=\frac{1-x_{p}}{3}-\frac{\alpha_{i}}{6}\left[x_{p}-\frac{1-x_{p}}{3}\right]-\frac{s \alpha_{i}}{6}\left[3 \frac{1-x_{p}}{3}\right],
$$

and the requirement $u_{i} \geq 0$ implies that the maximum share $x_{p}$ achievable by the proposer is

$$
x_{p}^{\max 1}=1-\frac{3 \alpha_{i}}{6+4 \alpha_{i}-3 s \alpha_{i}}
$$

Alternatively, the proposer can distribute $1-x_{p}$ equally among all members of both groups. Then, the responder's utility is

$$
u_{i}\left(x_{p}, \frac{1-x_{p}}{6}, \frac{1-x_{p}}{6}\right)=\frac{1-x_{p}}{6}-\frac{\alpha_{s}}{6}\left[x_{p}-\frac{1-x_{p}}{6}\right]
$$


Then, the maximum share $x_{p}$ achievable by the proposer is

$$
x_{p}^{\max 2}=\frac{6+\alpha_{i}}{6+7 \alpha_{i}}
$$

Equal distribution among all members is more beneficial for the proposer if the responder is highly inequality averse, i.e.

$$
x_{p}^{\max 2} \geq x_{p}^{\max 1} \Leftrightarrow \alpha_{i} \geq \frac{6}{6 s-1} .
$$

It is important to observe that a proposal that is acceptable for responder $i$ is also acceptable for any responder with a lower degree of inequality aversion than $i$. This is due to the fact that utility $u_{i}\left(x, \alpha_{i}\right)$ is monotonically decreasing in $\alpha_{i} \cdot{ }^{35}$ Note that $\frac{\partial x_{p}^{\max 1}}{\partial \alpha_{i}}<0$ and $\frac{\partial x_{p}^{\max 2}}{\partial \alpha_{i}}<0$, which implies that the maximum acceptable claim $x_{p}$ is the lower the more inequality averse the responder is. Note that equal distribution is only more profitable for the proposer for quite extreme social preferences: if $s \rightarrow 1$, the requirement is $\alpha_{i}>1.2$, if $s=0.5$, then the requirement is $\alpha_{i} \geq 3$, which is a rather high value of $\alpha$.

Now we are in the position to compare the optimal proposer shares in our four treatments. Note that for different decision rules and different compositions of the decision committee, the proposal has to be acceptable for a certain number of members of the strong group, and possibly also for the representative of the weak group within the decision committee. The final observation of the previous paragraph (that the maximum achievable proposer share decreases in $\alpha_{i}$ ) allows us to make use of the concept of order statistics in order to derive further insights on optimal proposer decisions. In the following we denote by $\alpha_{(k: n)}$ the $k^{\text {th }}$ order statistic of $n$ independent random draws from a distribution $F(\alpha)$ on $[0, \bar{\alpha}]$. In general, the distribution of $\alpha_{(k: n)}$ is given by

$$
F_{(k: n)}(y)=\sum_{j=k}^{n} \frac{n !}{j !(n-j) !} F(y)^{j}(1-F(y))^{n-j}
$$

In order to prove part (i) of the proposition we need the following distributions in our analysis:

$$
\begin{aligned}
& F_{(3: 3)}(\alpha)=F(\alpha)^{3} \\
& F_{(2: 3)}(\alpha)=3 F(\alpha)^{2}(1-F(\alpha))+F(\alpha)^{3} \\
& F_{(2: 2)}(\alpha)=F(\alpha)^{2} \\
& F_{(1: 1)}(\alpha)=F(\alpha)
\end{aligned}
$$

Let us first consider treatment U30, M21, and M30 for the case where $x_{w}=0$. In order to rank proposals across treatments with respect to $x_{p}$, denote the number of members from the strong group in the decision committee by $S$ and the number of votes from the strong group necessary for approval by $k$. Then, the proposer maximizes expected utility (recall that we assumed a risk neutral proposer

\footnotetext{
${ }^{35}$ This property hinges on our assumption that $\beta_{i}=s \alpha_{i}$. In the paper we also comment on the case that this does not hold true.
} 
without social preferences)

$$
E\left[u_{p}\left(x, \beta_{p}\right)\right]=P\left(u_{s}\left(x, \alpha_{(k: S)}\right) \geq 0\right) x_{p},
$$

In the scenario we analyze it holds that $x_{w}=0$, and thus, $x_{p}=1-3 x_{s}$. Using this and inserting $u_{s}(x, \alpha)$ as given in (3) we can express the probability of acceptance solely in terms of $x_{p}$, i.e.

$$
\begin{aligned}
P\left(u_{s}\left(x, \alpha_{(k: S)}\right)\right) & =P\left(\left[x_{s}-\frac{\alpha_{(k: S)}}{6}\left(x_{p}-x_{s}\right)-\frac{s \alpha_{(k: S)}}{6}\left(3\left(x_{s}-x_{w}\right)\right)\right] \geq 0\right) \\
& =P\left(\alpha_{(k: S)} \leq \frac{(4-3 s) x_{p}-1+3 s}{6\left(1-x_{p}\right)}\right) \\
& =F_{(k: S)}\left(\frac{6\left(1-x_{p}\right)}{4 x_{p}+3 s\left(1-x_{p}\right)-1}\right)
\end{aligned}
$$

Consequently, the proposer's expected profit is

$$
E\left[u_{p}\left(x, \beta_{p}\right)\right]=F_{(k: S)}\left(\frac{6\left(1-x_{p}\right)}{4 x_{p}+3 s\left(1-x_{p}\right)-1}\right) x_{p}
$$

Now note that in U30 (M30, M21) the distribution $F_{(3: 3)}\left(F_{(2: 3)}, F_{(2: 2)}\right)$ is relevant. From (14), (15), and (16) it follows immediately that

$$
F_{(3: 3)}(y)<F_{(2: 3)}(y) \forall y \quad \text { and } \quad F_{(3: 3)}<F_{(2: 2)}(y) \forall y \text {, }
$$

i.e. we have a relation of first order stochastic dominance. From this it immediately follows that $x_{p}^{U 30}>x_{p}^{M 30}$ and $x_{p}^{U 30}>x_{p}^{M 21}$.

Now it remains to show that $x_{p}^{U 21}<x_{p}^{U 30}$ whenever it is optimal to propose $x_{w}=0$ in U30. To this aim consider the case that the proposer awards the same shares to both groups, which constitutes a lower bound for the optimal proposer share (the proposer might improve by awarding less to the weak group). A responder's utility then is

$$
E\left[u_{s}\left(x, \alpha_{s}\right)\right]=x_{s}-\frac{\alpha_{s}}{6}\left(x_{p}-x_{s}\right)
$$

Accounting for the fact that $x_{s}=\left(1-x_{p}\right) / 6$ it is easy to show that $E\left[u_{s}\left(x, \alpha_{s}\right)\right] \geq 0$ iff $\alpha_{s} \leq \frac{6\left(1-x_{p}\right)}{7 x_{p}-1}$. Thus, we have

$$
\begin{aligned}
E\left[u_{p}^{U 30}\left(x, \beta_{p}\right)\right] & =F_{(3: 3)}\left(\frac{6\left(1-x_{p}\right)}{4 x_{p}+3 s\left(1-x_{p}\right)-1}\right) x_{p}, \\
& =F\left(\frac{6\left(1-x_{p}\right)}{4 x_{p}+3 s\left(1-x_{p}\right)-1}\right)^{3} x_{p}
\end{aligned}
$$




$$
\begin{aligned}
E\left[u_{p}^{U 21}\left(x, \beta_{p}\right)\right] & =F_{(2: 2)}\left(\frac{6\left(1-x_{p}\right)}{7 x_{p}-1}\right) F_{(1: 1)}\left(\frac{6\left(1-x_{p}\right)}{7 x_{p}-1}\right) x_{p} \\
& =F\left(\frac{6\left(1-x_{p}\right)}{7 x_{p}-1}\right)^{3} x_{p}
\end{aligned}
$$

Thus, whenever it is optimal in U30 to make a proposal that implies $x_{w}=0$, it must hold that $x_{p}^{U 21}<x_{p}^{U 30}$.

Part (ii) (ii.a): Now consider the situation where both groups are represented in the decision committee and unanimity is required (treatment U21). In U21 the proposer would be constrained by the requirement that the proposal is acceptable for both members of the strong group in the decision committee, i.e. $\alpha_{(2: 2)}$ determines the acceptance probability. Moreover, the committee member from the weak group has to be willing to accept. His $\alpha$ parameter is distributed as $\alpha_{(1: 1)}$. In U21, the proposer's objective function is thus

$$
E\left[u_{p}\left(x, \beta_{p}\right)\right]=P\left(u_{s}\left(x, \alpha_{(2: 2)}\right) \geq 0\right) P\left(u_{s}\left(x, \alpha_{(1: 1)}\right) \geq 0\right) u_{p}\left(x, \beta_{p}\right)
$$

The distributions of the relevant order statistics are

$$
\begin{aligned}
& F_{(2: 2)}(\alpha)=F(\alpha)^{2} \\
& F_{(1: 1)}(\alpha)=F(\alpha)
\end{aligned}
$$

Note that for all $\alpha$ it holds that $F_{(2: 2)}(\alpha)=F(\alpha)^{2}<F_{(1: 1)}(\alpha)=F(\alpha)$. Thus, starting from a proposal that awards equal proportions to members of both groups a proposer who plans to distribute additional amounts among the receivers in order to increase the acceptance probability would always consider only the strong group. Thus, the optimal proposal will always award a higher share to members of the strong group unless the proposer expects an extremely high degree of inequality aversion of the critical responder from the strong group. Then, the optimal proposal would automatically imply $x_{s}=x_{w}$.

(ii.b): The critical value of $\alpha$ has been shown in the proof of part (i) of the proposition. Do to the fact that $\alpha$ and $\beta$ enter linearly into the utility function, either $x_{s}=x_{w}$ or $x_{s}>0$ and $x_{w}=0$ is optimal.

(ii.c): In order to prove part (ii.c) of proposition 1, consider now the situation where only the strong group is represented in the committee (U30 and M30). In this case, the proposal should maximize the proposer's expected utility

$$
E\left[u_{p}\left(x, \beta_{p}\right)\right]=P\left(u_{s}\left(x, \alpha_{(k: 3)}\right) \geq 0\right) u_{p}\left(x, \beta_{p}\right),
$$

where $k=3$ in $\mathrm{U} 30$ and $k=2$ in M30.

Note that in case the most inequality averse responder has an $\alpha_{i} \geq \frac{6}{6 s-1}$, the proposer can claim 
a higher share for herself if she awards equal shares to all receivers from both groups. This event is clearly more likely in U30 than in M30 since $F_{(3: 3)}(\alpha)<F_{(2: 3)}(\alpha) \forall \alpha$. Thus, in expectation optimal proposals should more often award equal shares to all receivers.

(ii.d): Finally, consider M21. In M21, the proposer has two possibilities to get a majority of votes from the decision committee. Either the proposal convinces both committee members from the strong group (then, $\alpha_{(2: 2)}$ is relevant); or she convinces one committee member from the strong and one from the weak group (then, $\alpha \mathrm{s}: \alpha_{(1: 2)}=$ and $\alpha_{(1: 1)}$ are relevant). In M21, the objective function is thus

$E\left[u_{p}\left(x, \beta_{p}\right)\right]=\max \left\{P\left(u_{s}\left(x, \alpha_{s(2: 2)}\right) \geq 0\right) u_{p}\left(x, \beta_{p}\right), P\left(u_{s}\left(x, \alpha_{s(1: 2)}\right) \geq 0\right) P\left(u_{s}\left(x, \alpha_{w(1: 1)}\right) \geq 0\right) u_{p}\left(x, \beta_{p}\right)\right\}$

The distribution of $\alpha_{(1: 2)}=$ is given by

$$
F_{(1: 2)}(\alpha)=2 F(\alpha)(1-F(\alpha))+F(\alpha)^{2}
$$

Now let us consider the proposer's two alternatives: If she expects that inequality aversion is not too pronounced among the responders, the optimal proposal that awards zero to members of the weak group need to be acceptable for the strong responder with the higher degree of inequality aversion. Alternatively, the proposer could aim at satisfying one responder from each group. This would imply positive shares for both groups. The relevant inequality aversion parameters would be $\alpha_{\mathrm{s}}: \alpha_{(1: 2)}=$ and $\alpha_{(1: 1)}$. Note that $F_{(1: 2)}(\alpha)>F_{(1: 1)}(\alpha)$. Thus, awarding additional money to the weak group has a stringer effect on the acceptance probability than awarding additional money to the strong group. Thus, if both groups are awarded positive shares, the weak group should receive more.

Note, of course, that a proposer expecting a high degree of inequality aversion should supply both groups equally.

Part (iii) Finally consider ex ante communication among the proposer and the committee members. Whereas communication that tries to affect the own share of the pie is clearly cheap talk, communication that tries to affect the share others get is not. Obviously, in our bargaining game each responder clearly has an incentive to reveal his preferences with respect to the share that others should get truthfully. By doing so he or she can give the proposer a credibly hint on the nature of acceptable proposals. 


\section{A.2 Chat Protocols - Examples}

We now give representative examples of the sequences of the chat protocols for each treatment. Here, we follow the procedure of Kimbrough et al. (2008) and Fonseca and Normann (2012). These papers have shown that quoting chat protocols may reveal important details about subjects' behavior in communications. We use the following abbreviations: "Strong Group" (SG); "Weak Group" (WG).

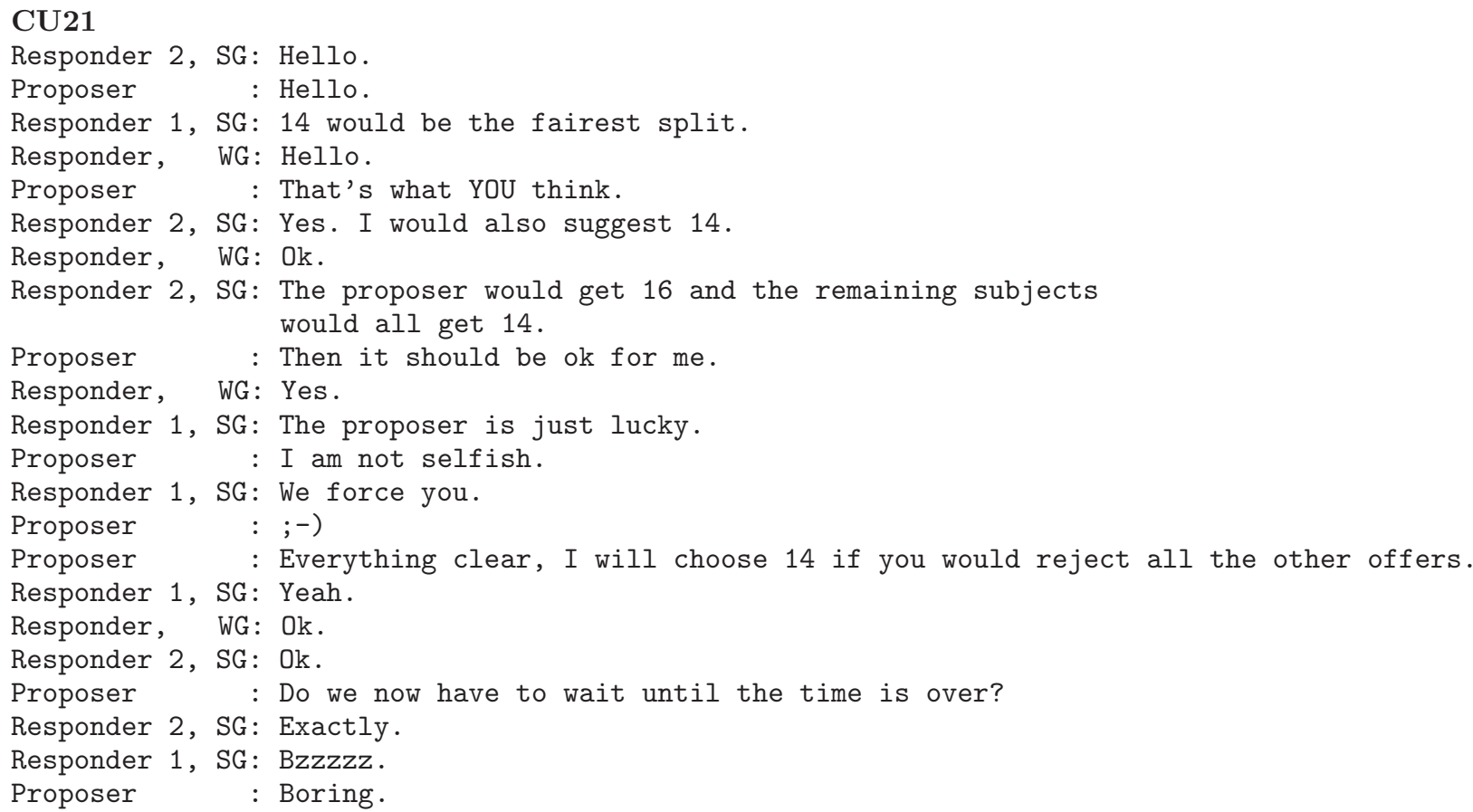

The latter dialogue is a representative example for most of the chats in CU21. Remarkably, both responders of the strong group immediately opt for the fair allocation where the group members of the strong and weak group would both get 14 . The proposer only once makes a query and responders immediately state again that they prefer the fair allocation. The proposer quickly agrees and mentions that she does that because he realized that all other offers would be rejected. Thus, the communication option seems to have meaningful impact on subjects' coordination.

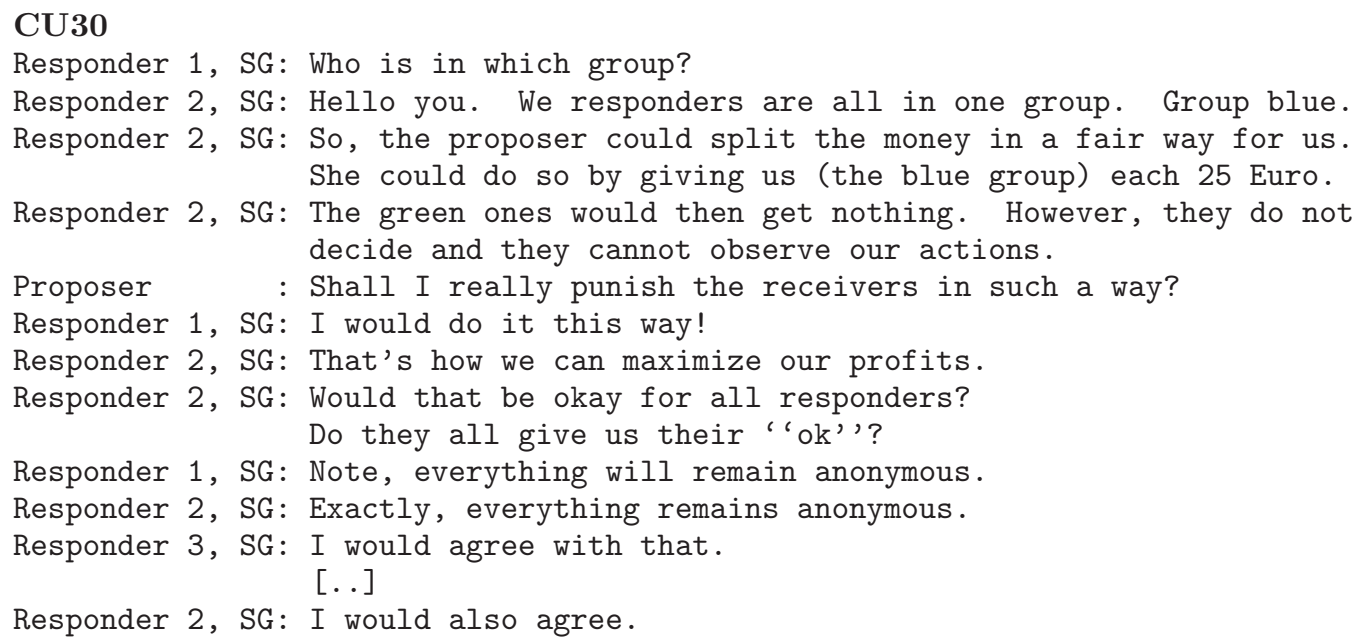


Responder 1, SG: I agree.

Proposer : It looks like the poor receivers will almost be left out in the cold.

Responder 1, SG: However, if the proposer does not propose the share we decided on, I will reject the poroposal

Responder 3, SG: Yet, it is the general idea that the others do not get anything.

Proposer : Yes, I agree, 25 Euro for everybody.

Responder 1, SG: Good.

Responder 1, SG: Ok.

Responder 1, SG: Well, that is 25 Euro for blue and 0 Euro for green.

Proposer : Exactly.

This example emphasizes that the chat participants do not explicitly talk about the fair allocation when the weak group is not presented. Responders of the strong group immediately suggest the unfair split (25 Euro for their group; 0 Euro for the weak group). Although the proposer realizes that this would not be fair, she agrees on that. Furthermore there is evidence that responders even threat (see responder 1) the proposer that they would reject if the proposer does not send the proposal they agreed on.

\section{CM21}

Proposer : Suggestion: 15 for the green ones and 10 for the blue ones.

Responder 2, SG: 20 for the green ones and 5 for the blue ones.

Responder 1, SG: Let's say 20 for the green ones.

Responder, WG: My suggestion would be: 14 blue, 14 green, proposer 16.

Responder 2, SG: 20 for green, the rest can be decided by the proposer.

Proposer : But this would be a little unfair.

Responder 1, SG: That's ok.

Responder 2, SG: 18 green, 10 blue, proposer 16 .

Responder 1, SG: Not unfair but economically.

Proposer : That would be ok for me.

Responder 2, SG: 18 green, 9 blue, proposer 19.

Responder, WG: Yes, if I would be you, I would also try to get as much as possible. Hence, it is clear that the blue group should get more than the green one.

Responder 1, SG: green 18, blue 7?

Responder 2, SG: $7+2.50$ Euro is still enough money.

Proposer : Yes okay.

Responder 2, SG: For this short amount of time.

Responder 1, SG: Very good.

Proposer : So green 18. You agree?

Responder 2, SG: Yes.

Responder 1, SG: Yes.

Proposer : Good.

This conversation clearly mirrors that the weak group has less bargaining power under the majority rule. The chat participants rarely explicitly mention the fair allocation (it is only mentioned uniquely in the beginning by the weak group's responder). Interestingly, even the responder of the weak group admits that she can understand that the strong group should get more which clearly demonstrates how subjects interpret the decision rules.

CM30

Proposer : Good starting position :-D.

Responder 3, SG: I would think economically, i.e., each of us 25 Euro.

Responder 1, SG: Yes.

Responder 2, SG: Yes.

Proposer : I would say, I get 28 and you 24.

Responder 3, SG: Above all, why? 


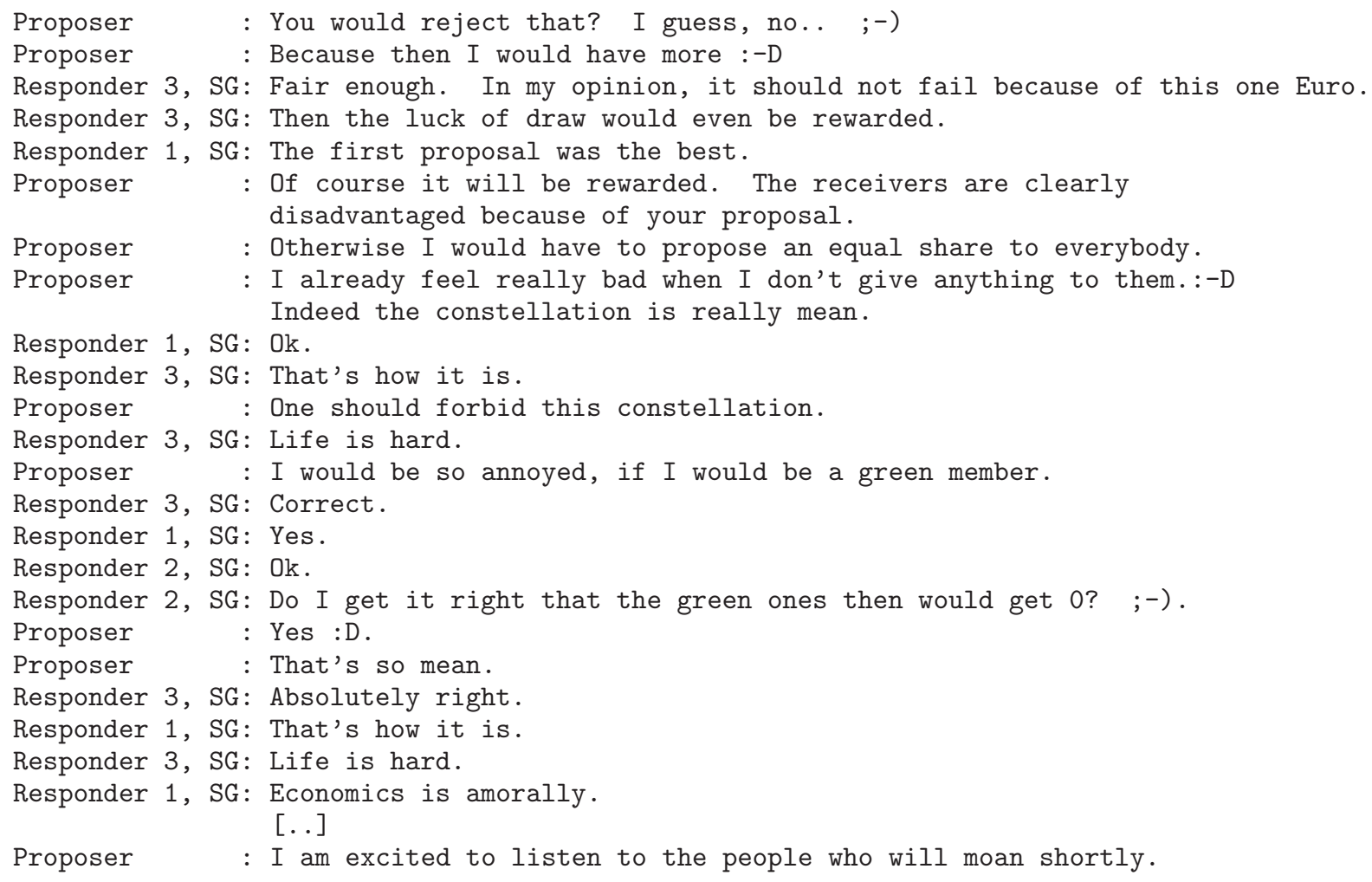

This dialogue clearly demonstrates that responders and proposers discuss most often unfair allocations under the unanimity decision rule when the weak group is absent. Although the proposer repeatedly mentions that she feels not well when treating people badly, she agrees on the unfair split. The reason is that the three responders of the strong group repeatedly encourage her to do so. A conspicuous finding is that the discussants often use terms like "life is hard" or "that's how it is" which may be used to justify their decision. 


\section{A.3 Instructions (for Treatments U21 and U30)}

\section{(translated from German)}

\section{Instructions to the experiment}

Welcome to today's experiment!

For your arrival on time you receive 2,50 Euros. In the course of the experiment you will have the opportunity to earn additional money. This depends on your actions and on the actions of the other participants in the experiment.

The total amount of your payoffs will remain entirely anonymous, i.e., we will not inform any of the other participants on your payoff. All participants will act entirely anonymous.

During the whole experiment you will be prohibited to communicate to any of the other participants.

Compliance to these rules is very important. If this is ignored, the results of the experiment will be of no importance for research. If you should have any questions, please raise your hand. We will then immediately come to your desk and answer your questions individually. 


\section{Groups}

In the beginning oft he experiment you will be randomly matched in a group of seven persons. One of these persons will be randomly allocated the role of a "proposer". The remaining six person will be randomly allocated to a blue and a green group, each consisting of three persons. Three subjects of the six subjects in the blue and green group will randomly allocated the role of "responders". The remaining three subjects in the blue and the green group will be "receivers". Four constellations (1-4) are possible for the random determination of three "responders" in the blue and the green group. Each constellation is possible with the same probability:

Constellation 1:

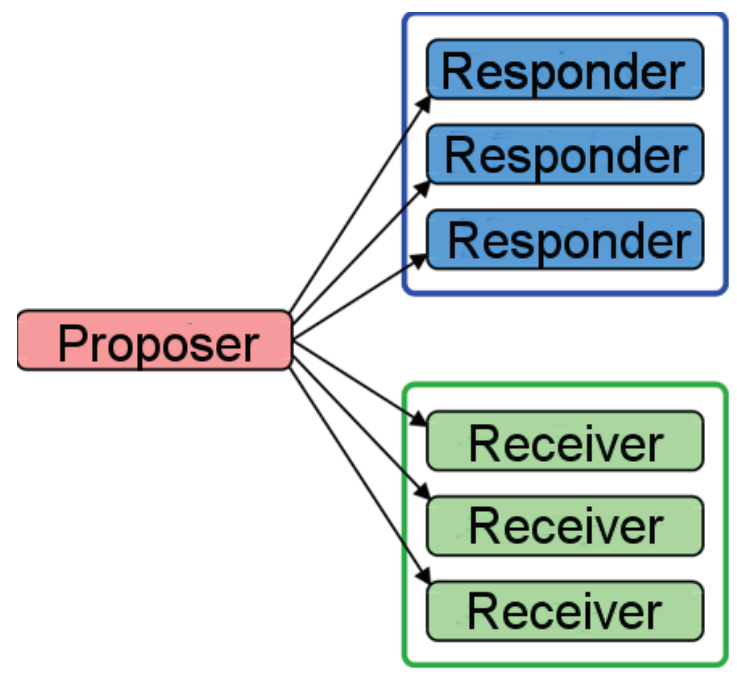

Constellation 3:

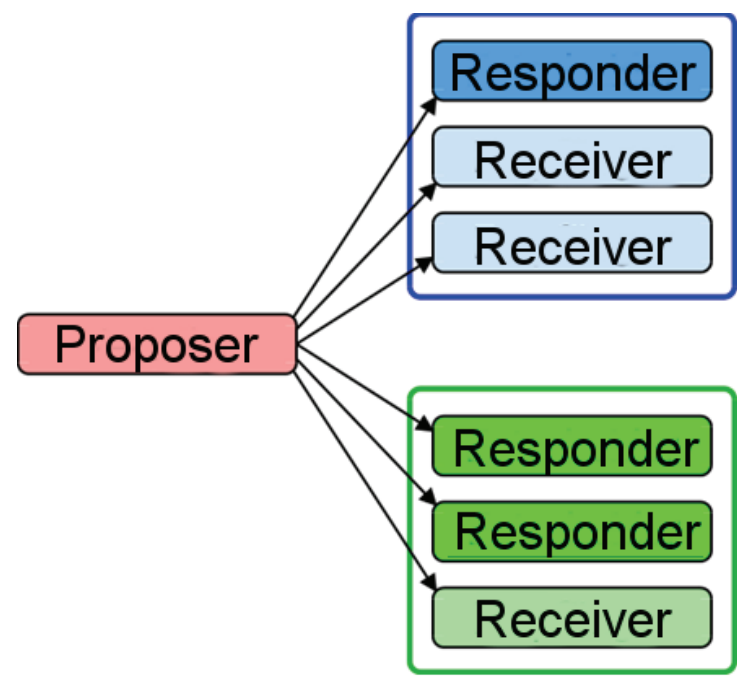

Constellation 2:

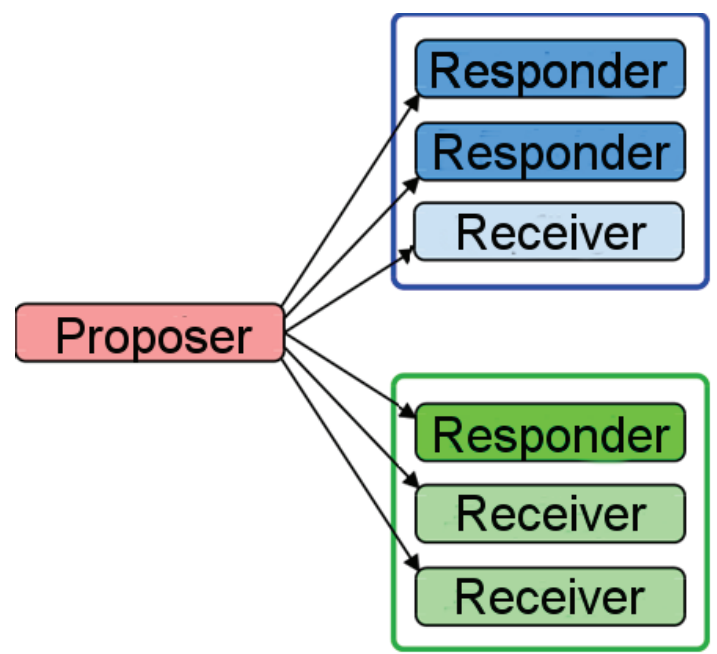

Constellation 4:

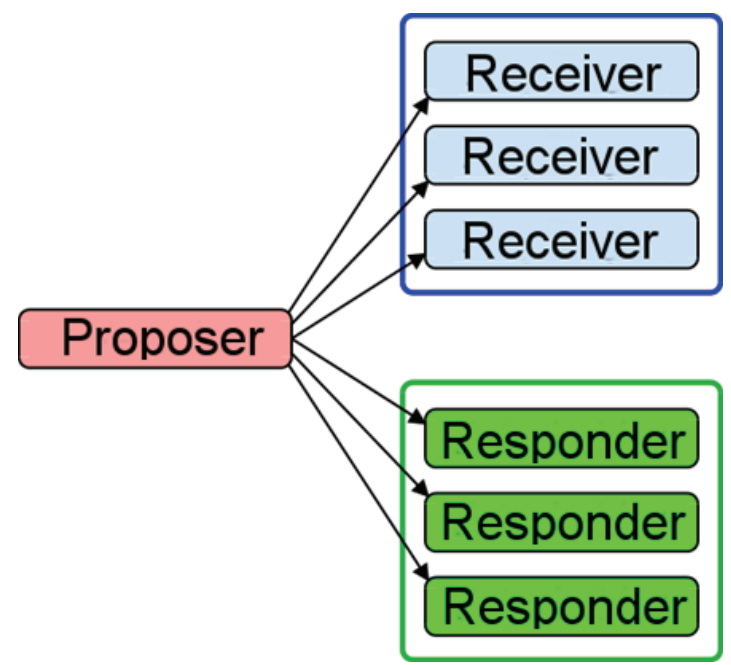

The roles and the matching into the groups will be unchanged during the whole experiment. In the course oft he experiment you will only interact with persons oft he 7-person group you are matched in. 


\section{Decisions and Proceedings in the Game}

In the beginning you will be informed on:

- The constellation which was selected

- Your role in the experiment

\subsection{Role of the Proposer}

The proposer will be endowed with 100 Euros. The proposer will be asked to allocate the 100 Euros between herself and the other six persons. When deciding on the allocation, the proposer has to stick to the following rules:

- All three members of the blue group must be allocated an equal share;

- All three members of the green group must be allocated an equal share;

- The 100 Euros must be allocated entirely

Several possible allocations are depicted in the handed out table. It can be read as follows:

- the first column (green background) reports the payoff for all three members of the green group;

- the first row (blue background) reports the payoff for all three members of the blue group;

- the cells with red background represent with the corresponding row value (payoff for all three members of the green group) and the corresponding column value (payoff for all three members of the green group) the corresponding value for the proposer.

- all combinatios in the table are possible. It can be calculated as follows:

$3 \times$ row value (green group) $+3 \times$ columne value (blue group) + proposer value $($ red $)=100$.

The proposer has to visualize a possible allocation in a cake diagram, after he has entered it in the prepared cells. If the proposer does not like the proposal she can change it how often she wants to do so. Afterwards she has to visualize it again. Finally, the proposer submits the proposal tot he three responders in the blue and red group.

\subsection{Role of the responders}

All three responders receive information on the proposed alloaction by the proposer in numbers and in a visualized way (cake diagram). 
All three responders have to decide whether they will accept or reject the proposal oft he proposer. The proposed proposal will only be processed when all three respondes accept the proposal. By contrast, none oft he seven persons will receive a payoff, if one or more responders rejects the proposal of the proposer.

\subsection{Role oft he receivers}

All three receivers cannot decide in the experiment. In the end they will only be informed on their own payoff.

\subsection{Informations for the participants}

After the three responders have decided on acceptance or rejectance of the proposal the proposer and the responders are informed on

- all single decisions of the three responders. They are also informed on the group memberships to the blue or green group;

- they receive information on all payoffs for the seven persons.

In the end the three receivers are only informed on their own payoff. 


\subsection{Examples}

\section{Example 1:}

In this example constellation 2 was chosen and you are in the role of the responder in the blue group. The proposer proposes the following possible allocation oft he 100 Euros:

\begin{tabular}{|c|c|c|c|c|c|c|}
\hline Proposer & Responder & Responder & Receiver & Responder & Receiver & Receiver \\
\hline $\mathrm{x}$ & $\mathrm{y}$ & $\mathrm{y}$ & $\mathrm{Y}$ & $\mathrm{z}$ & $\mathrm{z}$ & $\mathrm{z}$ \\
\hline
\end{tabular}

You and the other two responders accept the proposal. Thus, there will be the following payoff:

y Euro

\section{Example 2:}

In this example constellation 4 was chosen and you are in the role of the proposer. You propose the following possible proposal of the 100 Euros:

\begin{tabular}{|c|c|c|c|c|c|c|}
\hline Proposer & Receiver & Receiver & Receiver & Responder & Responder & Respoder \\
\hline $\mathrm{x}$ & $\mathrm{y}$ & $\mathrm{y}$ & $\mathrm{y}$ & $\mathrm{Z}$ & $\mathrm{z}$ & $\mathrm{z}$ \\
\hline
\end{tabular}

One responder rejects your proposal, the other two responders accept it. Ein Entscheider lehnt Ihren Vorschlag ab, die anderen zwei Entscheider nehmen Ihren Vorschlag an. Thus, there will be the following payoff:

\section{$\underline{\text { OEuro }}$}

\section{Example 3:}

In this example Constellation 1 was chosen and you afe in the role of a receiver in the green group. The proposer proposes the following possible proposal oft he 100 Euros:

\begin{tabular}{|c|c|c|c|c|c|c|}
\hline Proposer & Responder & Responder & Responder & Receiver & Receiver & Receiver \\
\hline $\mathrm{x}$ & $\mathrm{y}$ & $\mathrm{y}$ & $\mathrm{y}$ & $\mathrm{z}$ & $\mathrm{z}$ & $\mathrm{z}$ \\
\hline
\end{tabular}

All three responders accept the proposal. Thus, there will be the following payoff:

\section{z Euro}




\section{Example 4:}

In diesem Example Constellation 3 was chosen and you are in the role of a responder in the blue group. The proposer proposes the following possible proposal of the 100 Euros:

\begin{tabular}{|c|c|c|c|c|c|c|}
\hline Proposer & Responder & Receiver & Receiver & Respnder & Responder & Receiver \\
\hline $\mathrm{x}$ & $\mathrm{y}$ & $\mathrm{y}$ & $\mathrm{y}$ & $\mathrm{z}$ & $\mathrm{z}$ & $\mathrm{z}$ \\
\hline
\end{tabular}

You and one responder in the green group reject the proposal. The second responder oft he green group accepts the proposal. Thus, there will be the following payoff:

\section{O Euro}

\section{Sequel of decisions}
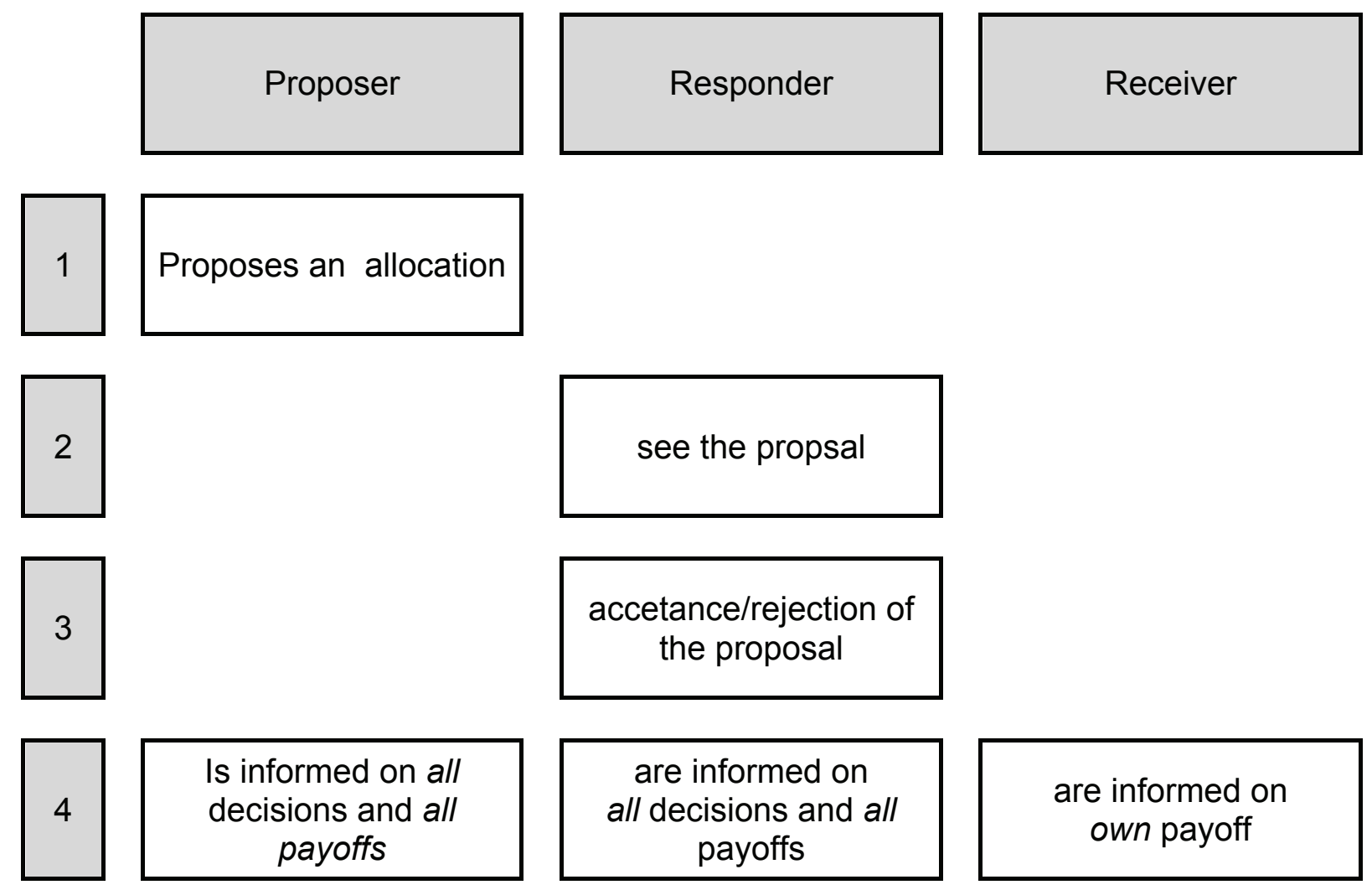
ed on all payoffs

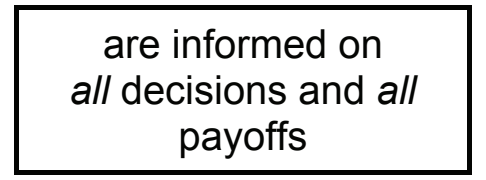

are informed on own payoff

Please consider that you make your decision only once. Therefore make your decisions carefully and take your time to decide. 


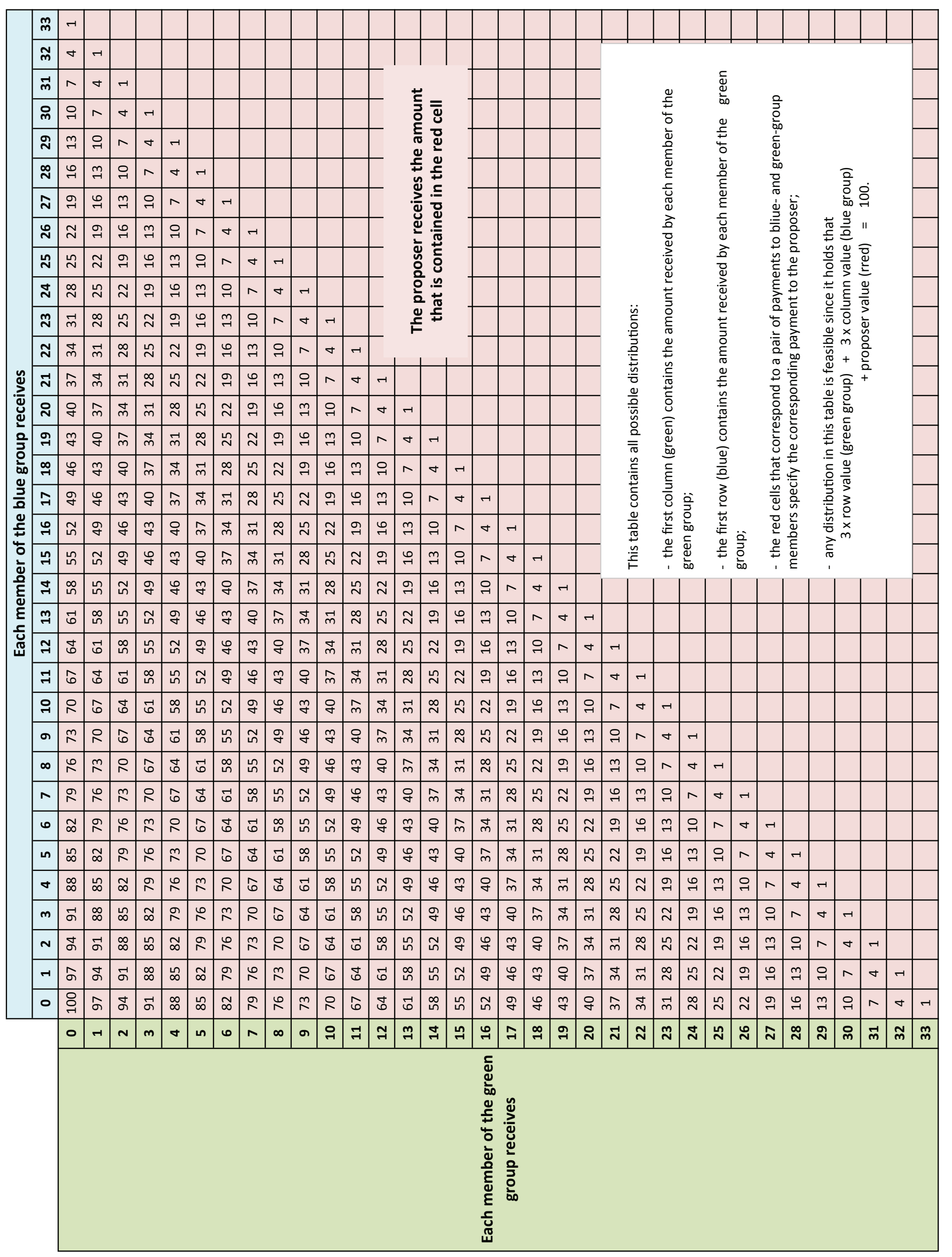

